Running head: DOES MAXIMIZING GOOD MAKE PEOPLE LOOK BAD?

Does Maximizing Good Make People Look Bad?

Andres Montealegre ${ }^{\mathrm{a}, \mathrm{b}}$, Lance S. Bush ${ }^{\mathrm{a}}$, David Moss ${ }^{\mathrm{c}}$, David Pizarro ${ }^{\mathrm{a}}$, and William Jimenez-

$$
\text { Leal }^{\mathrm{b}}
$$

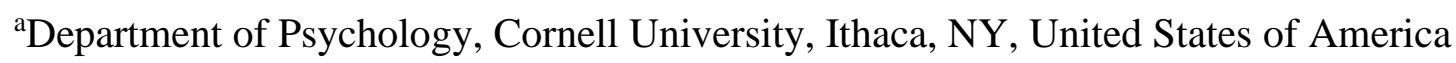

bepartment of Psychology, Universidad de los Andes, Bogotá, Colombia ${ }^{\mathrm{c}}$ Faculty of Education, Canterbury Christ Church University, Canterbury, United Kingdom

Draft version 3, 2021/11/23. This paper has not been peer reviewed. Please do not copy or cite without author's permission.

\author{
Author Note
}

This research was supported by a Small Research Grant Program from SPSP, a research fellowship awarded to Andres Montealegre by the Office of the Vice-president of Research and Knowledge Creation of Universidad de los Andes, and a Young Researcher program awarded to Andres Montealegre by Colombia's Administrative Department of Science, Technology and Innovation (Colciencias). We thank Eric Uhlmann, Stefan Schubert, Rachel King, Stephanie Tepper, Aurélien Allard, and Rajen Anderson for helpful feedback and advice. The pre-registrations, data, code, materials, and supplemental materials can be found on the Open Science Framework (https://osf.io/g888d/?view_only=62d344ecd72f4679a6015753c574bd98).

Correspondence concerning this article should be addressed to Andres Montealegre, Department of Psychology, Cornell University, Ithaca, NY, United States of America. Email: am2849@cornell.edu 
DOES MAXIMIZING GOOD MAKE PEOPLE LOOK BAD?

\begin{abstract}
People often fail to prioritize the cost-effectiveness of charities when donating. We propose that people donate ineffectively, in part, to avoid the reputational costs of deliberating about the cost-effectiveness of charities, rather than empathizing with the recipients of the donation. Across nine pre-registered studies conducted among US MTurk participants and effective altruists, we present two findings that are consistent with this claim. First, we find that “deliberators" are perceived as less moral and less desirable as social partners than "empathizers". We show that this result holds across different experimental designs (between-subjects, within-subjects), moderating factors (targets of different genders, donations of different stakes), and paradigms (evaluating a survey respondent, evaluating a person donating to charity). We also rule out an alternative explanation to this finding (that the result is explained by a misunderstanding of what donating to the most cost-effective charity means). Second, we find that people correctly anticipate the negative reputational costs of deliberating. Namely, people are aware that deliberating about the cost-effectiveness of charities leads others to evaluate them as less moral and less desirable social partners. Taken together, our results are consistent with the possibility that there are disincentives for selecting charities based on deliberation about the cost-effectiveness of charities, since people are not socially rewarded for prioritizing charitable impact but are rewarded for possessing the moral traits that others perceive to be important, hence explaining why people donate ineffectively. We end by discussing implications and limitations of these findings.
\end{abstract}

Keywords: moral judgment, effective altruism, reputation, empathy, utilitarianism 
DOES MAXIMIZING GOOD MAKE PEOPLE LOOK BAD?

\section{Does Maximizing Good Make People Look Bad?}

A remarkable feature of humans is their willingness to help others who are not family, friends, acquaintances, or part of their social circle. People donate large sums of money to charities to help strangers whom they might never meet (e.g., 450 billion USD in the United States in 2019; Giving USA 2020, 2020). Given that charities differ vastly in their costeffectiveness, donating to the most cost-effective charities can dramatically increase the impact of donations. ${ }^{1}$ Despite donors' altruistic efforts, their help is limited by the fact that their donations do not typically go to the most cost-effective charities (MacAskill, 2015; Ord, 2013). Even though people report caring about the impact of their donations (Caviola, Schubert, \& Nemirow, 2020; Hope Consulting, 2010), research suggests that they often fail to prioritize cost-effectiveness when donating (Baron \& Szymanska, 2011; Berman et al., 2018; Caviola et al., 2021; Caviola, Schubert, \& Nemirow, 2020; Simler \& Hanson, 2017). Why would well-meaning donors reduce the impact of their help?

Two explanations have been proposed to explain ineffective giving (Caviola et al., 2021; Caviola, Schubert, \& Nemirow, 2020). According to the belief-based explanation, ineffective giving results from a lack of adequate information or from misconceptions. For instance, people are unfamiliar with the most effective charities (Caviola, Schubert, \& Nemirow, 2020), and they dramatically underestimate the gap in effectiveness between the most effective and the average charities (Caviola, Schubert, Teperman, et al., 2020). Moreover, providing people with adequate or correcting information (e.g., explaining that high overhead costs do not necessarily mean that a charity is less cost-effective) partially reduces, but does not eliminate, ineffective giving (Caviola, Schubert, \& Nemirow, 2020). ${ }^{2}$

\footnotetext{
${ }^{1}$ In this context, cost-effectiveness refers to the amount of good done by a charity, e.g., number of lives saved, divided by the amount of resources spent to bring about that outcome (MacAskill, 2015).

2 This explicit debiasing approach probably overestimates the extent to which ineffective giving would be fixed by providing adequate information since it runs the risk of introducing demand effects due to the implied pressure to select the most effective option.
} 
DOES MAXIMIZING GOOD MAKE PEOPLE LOOK BAD?

In contrast, the preference-based explanation proposes that there are various reasons why donors do not prioritize effectiveness, even if they have adequate information. This does not mean that donors do not care about cost-effectiveness, but that there are other considerations that win out over cost-effectiveness. For example, when given the opportunity to consult information about the cost-effectiveness of charities, only a small fraction of people check this information (Metzger \& Günther, 2019). Instead, people prefer to consult information about the recipients of the donation. Moreover, although people recognize that a distant charity is more cost-effective, people think that donors should donate to a local charity with which donors have an emotional connection (Berman et al., 2018). In addition, people's emotional responses get in the way of donating effectively, since people are more moved by identifiable victims over statistical victims (Small \& Loewenstein, 2003), and people value interventions helping a fixed number of people more when fewer victims are involved overall (Fetherstonhaugh et al., 1997). More generally, people donate to local over distant charities, even though many distant charities are more cost-effective given the huge differences in living conditions, and donors prefer to support charities with which they have an emotional connection, even though these charities are less effective (Caviola, Schubert, \& Nemirow, 2020). Furthermore, when people are asked to decide between otherwise identical charities or investments, fewer people sort the charities in terms of effectiveness compared to the investments and fewer people select the most effective charity compared to the most effective investment (Berman et al., 2018). Arguably, this preference-based obstacle is harder to overcome since promoting effective giving requires changing people's preferences rather than correcting misconceptions (Caviola, Schubert, \& Nemirow, 2020).

Although current accounts distinguish between ineffective giving due to lack of information or misinformation and ineffective giving due to other preferences apart from maximizing cost-effectiveness, these accounts do not explain why we should expect a 
DOES MAXIMIZING GOOD MAKE PEOPLE LOOK BAD?

psychology that favors ineffective giving. Existing accounts have focused almost exclusively on explaining the proximal psychological barriers of effective giving, i.e., beliefs, preferences and emotions that favor ineffective giving, but have not explored the potential evolutionarily adaptive function of a psychology that favors ineffective giving, i.e., what evolutionary challenges these beliefs, preferences and emotions help solve (Caviola, Schubert, \& Nemirow, 2020; Cosmides et al., 2018). ${ }^{3}$ In this paper, we examine the adaptive role of a psychology that favors ineffective giving.

We introduce a reputational account to explain ineffective giving that distinguishes between donation decisions that signal deliberation about the impact of charities (i.e., evaluating the cost-effectiveness of the donation) or empathy for the recipients of the donation (i.e., experiencing what you infer other people are feeling; Bloom, 2017; Loewenstein et al., 2015). ${ }^{4}$ We propose that donating empathically signals that one has good moral character and is a valuable social partner, given that reacting empathically to recipients of the donation signals an honest concern about the beneficiaries and a reliable motivation to act prosocially (Barasch et al., 2014; Uhlmann et al., 2015). In contrast, donating deliberatively may signal less concern and prosocial motivation, given that it signals that a donor is guided by pragmatic considerations (e.g., is this the most cost-effective charity?)

\footnotetext{
3 There are a few exceptions to this pattern. Simler and Hanson (2017) argue that people donate ineffectively, in part, because evolution favored adaptations that help us advertise our qualities as social partners which are in conflict with donating effectively. Jaeger and van Vugt (2022) argue that people donate ineffectively because evolution favored adaptations that steer us towards parochialism, status-seeking, and conformity, which are in conflict with donating effectively. As will become obvious, our proposal is consistent with both of these accounts. Note, however, that their proposals are theoretical (i.e., they are based on reinterpreting existing evidence). To our knowledge, there is only one empirical paper that proposes an evolutionary account of ineffective giving. Burum and collaborators (2020) argue that ineffective giving is explained by the fact that a donation's impact is not socially well defined or observable. This proposal is consistent with ours, although it differs in focus. Their focus is on explaining why donors are not more sensitive to effectiveness, but not on the signaling implications of effective donations. Although we agree that part of the reason behind ineffective giving is that donors do not get credit for donating effectively, our account focuses on the information that donating effectively provides about the donor (e.g., less valuable social partner).

${ }^{4}$ In presenting a distinction between empathy and deliberation, we do not wish to give the impression that the two are psychologically distinct and in conflict with one another. The relationship between empathy and deliberation is probably more complex than suggested by dual process models (Helion \& Pizarro, 2015). However, our approach does not rest on a strong commitment to dual process models, but on the weaker assumption that donation decisions signal differing degrees of empathy or deliberation.
} 
DOES MAXIMIZING GOOD MAKE PEOPLE LOOK BAD?

rather than the feelings of the recipients of the donation. This could lead people to infer that deliberative donors are more cold, calculating, and pragmatic, and that they have a weaker commitment to interpersonal relationships, compared to empathic donors (Trivers, 1971). Given the importance of maintaining a good reputation for our social life and wellbeing (Barclay, 2015; Helliwell \& Putnam, 2004; Sperber \& Baumard, 2012), donors may intentionally or unintentionally donate in ways that convey empathy for the recipients of the donation rather than deliberation about the cost-effectiveness of charities. One prediction from our account is that people will anticipate different reputational consequences from donating based on empathy or deliberation. In particular, people will expect to be judged as less moral and less desirable social partners when donating based on deliberation rather than based on empathy. Additionally, for donors to be able to effectively adapt their behavior to signal certain qualities, other people evaluating them need to be sensitive to these signals (Sperber \& Baumard, 2012). Thus, another prediction of our account is that donors who donate based on empathy will be rated as more moral and more desirable social partners than those who donate based on deliberation. In this paper, we test these two predictions by (1) asking people to evaluate deliberative or empathic donors and (2) asking people to predict the reputational consequences of donating deliberatively or empathically.

Our reputational account is supported by two lines of research: research on empathy and moral behavior, and research on judgments about people who make utilitarian decisions. Research on empathy and moral behavior supports the idea that empathy is a reliable signal of people's moral character. This research offers an explanation for why signals of empathy lead to positive evaluations. In addition, research on judgments about people who make utilitarian decisions suggests that people gain little reputational benefit from increasing the impact of their donations and instead suffer reputational costs. This research offers an explanation for why signals of deliberation lead to negative evaluations. 
DOES MAXIMIZING GOOD MAKE PEOPLE LOOK BAD?

\section{Empathy and moral behavior}

People may assess whether other people are reliably altruistic by attending to emotional cues. When another person engages in an altruistic act, but exhibits no accompanying emotional response (such as feeling bad for the recipient of a donation) this could indicate that this person may not be reliably altruistic in the future. As Trivers explains: "Selection may favour distrusting those who perform altruistic acts without the emotional basis of generosity or guilt because the altruistic tendencies of such individuals may be less reliable in the future. One can imagine, for example, compensating for a misdeed without any emotional basis but with a calculating, selfserving motive. Such an individual should be distrusted because the calculating spirit that leads this subtle cheater now to compensate may in the future lead him to cheat when circumstances seem more advantageous (because of unlikelihood of detection, for example, or because the cheated individual is unlikely to survive)" (1971, pg. 51) Hence, emotional cues may signal a disposition to be altruistic. Although there are many relevant emotions that signal a disposition to be altruistic (Frank, 1988), we argue that empathy plays a central role in charitable donations, given that charitable donations typically involve people who are suffering or in need. In particular, inferring what those people who are suffering are feeling may signal a capacity to detect suffering and a motivation to alleviate it. In support of this claim, researchers have found that people infer prosocial feelings and motivations from signals of emotions, i.e., people infer that those who experience emotion are more likely to cooperate and are more likely to feel emotions like empathy and compassion (Levine et al., 2018). Additionally, other studies have found that donors who experience greater empathy are perceived to have a better moral character, and that this effect is reduced when the emotion felt does not lead to prosocial behavior (Barasch 
DOES MAXIMIZING GOOD MAKE PEOPLE LOOK BAD?

et al., 2014). As such, people who signal empathy when donating communicate their altruistic disposition, which in turn may increase their desirability as social partners.

If people who signal empathy are more altruistic, people who rely on such signals may benefit from doing so. One reason why signals of empathy may be honest (i.e., they reliably indicate that someone is altruistic) is that faking signals of emotions is risky or impractical. In particular, emotions, like empathy, are often involuntary and hard to fake, and trying to fake them is both cognitively demanding and risks being caught (Sperber \& Baumard, 2012). Consistent with empathy being an honest signal, donors who experience greater empathy are more likely to cooperate. In one study, people who made decisions based on emotion rather than deliberation were more likely to cooperate (Levine et al., 2018). More broadly, the literature on the 'empathy-altruism hypothesis' suggests that empathic concern promotes altruistic behavior (Batson, 2017), and a meta-analysis found a low to moderate relationship between empathy and prosocial behavior (Eisenberg \& Miller, 1987). As such, existing evidence is consistent with the possibility that feeling empathy in response to people suffering is an honest signal of a willingness to be altruistic.

Although empathy promotes altruism, it does not necessarily promote effective altruism. Researchers have pointed out that empathy is not a motivator of impartial helping behavior (Bloom, 2017), given that it is narrow in focus (e.g., people grant preferential treatment to a patient when they feel empathy for them) and it motivates aggression or cruelty (e.g., people are more likely to act aggressively towards the competitor of a person they empathize with). However, the same qualities that make empathy a source of biased helping behaviors also make empathy valuable in a friend or a social partner. We probably prefer to affiliate with empathic people who are willing to give preferential treatment to us (over other people), focus on our needs (over the needs of the larger group), and defend our interests, even when that means acting aggressively towards our competitors (Bloom, 2017). This 
DOES MAXIMIZING GOOD MAKE PEOPLE LOOK BAD?

highlights that there is a tradeoff between relying on empathy and cost-effective helping behaviors. To engage in impartial helping behaviors people need to avoid relying on their empathic instincts.

Not surprisingly, effective altruism has often been criticized for being too cold, impersonal, or calculating. For instance, in an article from the Stanford Social Innovation Review the authors write: "It is sadly thus that the very human impulse to help others and the mantra of Charity Navigator since its inception - that people should become informed donors and give with their heads as well as their hearts - have been infused with logic so cold that even Mr. Spock would cringe upon hearing it.” (Berger \& Penna, 2013). In an article from the Acton Institute that proposes 3 problems with effective altruism, the author writes: "First, effective altruism requires me to make a cold, impersonal hyper-utilitarian calculation in all of my decisions. It forces me to weigh temporarily helping my younger sister who has just suffered a major tragedy versus saving a person in the developing world from malaria." (Oetting, 2018). Other criticisms of effective altruism suggest similar points: "We submit both that love and fellow-feeling as opposed to the spirit of calculation are important dimensions missing from the EA analysis" (Earle \& Read, 2016 pg. 88). This is such a common criticism that the Effective Altruism website has an FAQ in which it addresses the question 'Is effective altruism calculating and impersonal?' (Frequently Asked Questions and Common Objections, n.d.). People worry that effective givers are cold, unreliable, or unpredictable social partners, since they seem only willing to help when it maximizes good. People also worry about the motives or the agenda of those who are guided by an abstract maximization of good but who seem unaffected by their emotions.

In sum, people's empathic reactions to the recipients of a charitable donation may provide an honest signal of their willingness to be altruistic. For this reason, people have a strong motivation to pay attention to cues of empathy when evaluating other people's moral 
DOES MAXIMIZING GOOD MAKE PEOPLE LOOK BAD?

character and selecting interaction partners. This research also suggests a reason why people might derogate effective givers: donating deliberatively may not strongly communicate empathy, and it may therefore lead to negative social inferences about the donor. There is also research that provides direct evidence that people dislike those who endorse an 'effective altruist' approach to helping, although this literature is not connected to the literature on emotion. It is to this research that we now turn.

\section{Research on judgments about people who make utilitarian decisions}

A large literature in moral psychology has examined whether people's moral intuitions conform more with utilitarian or deontological principles. To do this, researchers have primarily employed sacrificial dilemmas, like the trolley scenario, in which people are asked whether it is acceptable to sacrifice one or more people to save a greater number of lives (Bartels et al., 2015). In these scenarios, a utilitarian is said to be willing to sacrifice one or more people to save a greater number of lives, since they care about impartially maximizing aggregate welfare, whereas a deontologist is said to be opposed to doing this, even if it minimizes the number of people who die, since for them the rightness or wrongness of an action is based on principles or obligations rather than consequences (Everett et al., 2016). There has been an increasing recognition that responses to these dilemmas may, at best, capture only one component of utilitarianism, referred to as 'instrumental harm,' (i.e., a moral duty to harm some people to save a greater number of lives), but have failed to capture what is referred to as 'impartial beneficence,' (i.e., a moral duty to impartially maximize the wellbeing of sentient beings; Kahane et al., 2018).

This literature is relevant for our purposes since effective altruism could be characterized as an attempt to apply utilitarian ideas (see Schubert \& Caviola, 2021). Although there are differences between effective altruism and utilitarianism, (e.g., effective 
DOES MAXIMIZING GOOD MAKE PEOPLE LOOK BAD?

altruism does not make claims about 'moral obligation'), there are also important similarities, such as their shared concern with maximizing good and promoting the wellbeing of sentient beings (MacAskill, 2019). In fact, in a 2019 survey of effective altruists, a majority (70\%) identified with utilitarian consequentialism (Dullaghan, 2019). The 'impartial beneficence' component of utilitarianism is the most relevant since it comprises a willingness to help effectively. $^{5}$

Of relevance, there is an emerging line of research examining people's evaluations of others who make utilitarian or deontological judgments both in the domain of 'instrumental harm' and 'impartial beneficence.' For instance, in the domain of 'instrumental harm' (e.g., trolley scenarios) people who favor utilitarian responses are less preferred as social partners and are seen as less moral and less trustworthy (Everett et al., 2016, 2018; Uhlmann et al., 2013). But even more relevant, in the domain of 'impartial beneficence' (e.g., scenarios involving helping a family member vs. helping a greater number of strangers), people who favor non-utilitarian responses are preferred as partners for close relations (e.g., friend, spouse), and are seen as more loyal (Everett et al., 2018). These results are consistent with evidence that people who help strangers over family members are judged as less morally good and less trustworthy (McManus et al., 2020), and evidence that helping distant strangers over close others may have negative consequences for a relationship (Law et al., 2019). These findings underscore the negative reputational consequences that follow from taking an effective altruist approach to helping others. Even though people think that feeling for all people equally (Fowler et al., 2021) and maximizing the amount of good done are morally desirable (Caviola, Schubert, \& Nemirow, 2020), they derogate people who make the

\footnotetext{
${ }^{5}$ For instance, some of the items from the Oxford Utilitarianism Scale to measure 'impartial beneficence' are: "It is morally wrong to keep money that one doesn't really need if one can donate it to causes that provide effective help to those who will benefit a great deal" and "From a moral perspective, people should care about the well-being of all human beings on the planet equally; they should not favor the well-being of people who are especially close to them either physically or emotionally." (Kahane et al., 2018).
} 
DOES MAXIMIZING GOOD MAKE PEOPLE LOOK BAD?

tradeoffs necessary to favor these positions, (i.e., they are seen as less trustworthy, loyal or reliable social partners).

In addition to the reputational costs, effective givers do not get much credit for increasing the impact of their donations. Consistent with this, research shows that when praising good deeds people are more sensitive to the feelings associated with an action than with the consequences of the action (Yudkin et al., 2019). The authors even draw the connection to effective altruism: "In particular, our research suggests that this movement may be facing an uphill battle, because, while effective altruism encourages people to focus on consequences, we find that, in fact, deeds high in action value are considered most praiseworthy (Berman et al., 2018). As a result, it may be difficult for effective altruists to garner social praise for their actions." (Yudkin et al., 2019 pg. 8). Other research argues that people evolved to be insensitive to the effectiveness of donations, given that effectiveness is not socially well defined or observable. One study showed that participants reward donors only for giving (vs. not giving), but not depending on the effectiveness of their donation (Burum et al., 2020). In sum, effective donors not only face negative reputational costs for signaling undesirable traits, they also gain little credit for increasing the impact of their donations.

\section{Research Overview}

In this paper, we examine whether donors' failure to prioritize cost-effectiveness can be explained by reputational concerns. In doing so, our paper makes two key theoretical contributions. First, current accounts of ineffective giving focus on the proximal psychological barriers of effective giving, but not on the evolutionary adaptive function of ineffective giving. Here, we explore the adaptive role of a psychology that favors ineffective giving. In particular, we propose that donors may intentionally or unintentionally rely on 
DOES MAXIMIZING GOOD MAKE PEOPLE LOOK BAD?

empathy and avoid deliberating about the cost-effectiveness of helping others to maintain a good reputation. We find that people who donate by empathizing with the recipients of the donation are evaluated as more moral and more desirable social partners than people who donate by deliberating about the cost-effectiveness of charities, and that people are aware of these reputational consequences. Our account therefore suggests that ineffective giving may be explained, at least in part, by evolutionary pressures that favor strategies that maximize individual reputation-maintenance, at the expense of a more efficient societal allocation of helping resources. Second, we build on and integrate research on empathy and moral behavior as well as research on judgments of people who make utilitarian decisions. These research literatures have independently found that people gain reputational benefits from signaling empathy, and that people gain little reputational benefits from helping effectively. Here, we integrate these literatures by showing that people's reluctance to deliberate about the cost-effectiveness of charities as well as engage in other consequentialist decisions that involve deliberation may be explained by the reputational consequences that follow from signals of emotion or lack thereof. Despite the fact that donors who deliberate about the costeffectiveness of charities explicitly aim to maximize the impact of their help, they fail to get as much reputational credit as people who signal moral traits that indicate being a nice social partner, such as empathy. Our account therefore suggests that people are not socially rewarded for prioritizing impact but are rewarded for possessing the moral traits that others perceive to be important.

Across nine studies conducted among US MTurk participants and effective altruists, we test two predictions from this reputational account: (1) people will judge "deliberators" as having a worse moral character and as being less desirable as social partners than "empathizers" (Studies 1-7) and (2) people will anticipate being judged as less moral and less desirable social partners when deliberating rather than empathizing (Studies 8-9). In Studies 
DOES MAXIMIZING GOOD MAKE PEOPLE LOOK BAD?

1-7, we examined participants' evaluations of deliberative and empathic donors. In Studies 14 and 7, participants were presented with fictitious survey responses (which were presented as real) exhibiting either a deliberative or empathic approach to donating to charity. These studies establish that people judge "deliberators" as less moral and less desirable as social partners than "empathizers" across different designs and moderating factors, and rule out an alternative explanation to this finding. In Studies 1 and 2, we compared evaluations of deliberative and empathic responses using between-subjects and within-subjects designs, respectively. In Studies 3 and 4, we examined the moderating role of the gender of the person being evaluated and the stakes of the donation, respectively. In Study 7, we tested one potential concern with the manipulation of deliberation (that the result is explained by a misunderstanding of what donating to the most cost-effective charity means). Studies 5-6 extend these results to a more naturalistic scenario, contextualize our results (by introducing a comparison to non-donors), and test a potential intervention to reduce negative evaluations of “deliberators”. In Studies 5 and 6, we replicated and extended our prior results using a different scenario in which participants evaluated a person who was deciding whether to help a child living in extreme poverty. In Study 5, the person was described as either donating using a deliberative or empathic approach or not donating at all. In Study 6, we tested whether expressing empathy before deliberating could reduce the negative evaluations of “deliberators". In Studies 8-9, we examined if participants anticipate being evaluated more negatively if they deliberate about the cost-effectiveness of charities rather than if they empathize with the recipients of the donation. In Study 8, we examine this among lay people, while in Study 9 we examine this among effective altruists. In a study reported in the Supplemental Materials, we examined whether people who deliberate are trusted less than those who empathize in a trust game.

\section{Transparency and Openness}


DOES MAXIMIZING GOOD MAKE PEOPLE LOOK BAD?

For all studies, we report how we determined our sample sizes, all data exclusions, all manipulations, and all measures (Simmons et al., 2012). The design and analysis of all studies was pre-registered on AsPredicted (aspredicted.org), and the pre-registrations, data, code, materials, and supplemental materials can be found on the Open Science Framework (https://osf.io/g888d/?view_only=62d344ecd72f4679a6015753c574bd98). ${ }^{6}$ In addition to our main measures, we collected exploratory measures that are described in the studies but are not fully analyzed. In some studies, we made some deviations from the pre-registrations. ${ }^{7}$ All samples were Amazon Mechanical Turk participants based in the United States (Buhrmester et al., 2011), except Study 9 in which we recruited effective altruists. We determined the sample size in advance for all studies except Study 9, in which we recruited as many participants as possible. For all studies, no data analysis was conducted until we had a complete sample (as determined in the pre-registration). To guarantee adequate statistical power, we selected sample sizes that allow us to detect modest effect sizes, given a particular experimental design. For studies using between-subjects designs manipulating one factor (Studies 1, 5, and 6) we aimed for 100 participants per condition (excluding Study 7 in which we aimed for 200 participants per condition). For studies using within-subjects designs (Study 2 and Study 8) we aimed for 122 and 200 participants, respectively. For studies using a $2 \times 2$ factorial between-subjects design (Studies 3 and 4) we aimed for 517 participants per study. ${ }^{8}$ For Study 9 , we aimed to recruit as many participants as possible during a certain timeframe (out of a sample of 877 participants). For each study, we report sensitivity power analyses using $\mathrm{G}^{*}$ Power 3.1 (Faul et al., 2007) to estimate the effect sizes that we can detect

\footnotetext{
${ }^{6}$ Before sharing the data, we deleted private information (e.g., location information), removed participants who did not reach the end of the survey, and removed a participant who indicated being 3 years old (Study 3 ).

${ }^{7}$ Deviations from the pre-registrations and a few minor errors (e.g., typos) are explained in the Supplemental Materials. For all typos, we removed the errors in the paper but we left the materials and Qualtrics surveys unmodified.

${ }^{8}$ There were minor deviations from these intended sample sizes due to MTurk/CloudResearch software.
} 
DOES MAXIMIZING GOOD MAKE PEOPLE LOOK BAD?

with $90 \%$ power, a $5 \%$ alpha, and a given sample size. ${ }^{9}$ We also test the robustness and generalizability of our results by using different experimental designs (between-subjects, within-subjects), moderating factors (targets of different genders, donations of different stakes), and paradigms (evaluating a survey respondent, evaluating a person donating to charity), as well as ruling out alternative explanations. For all studies, participants provided their consent, then answered the measures, and finally answered sociodemographic questions (excluding Study 9 in which sociodemographic questions were presented before the measures). In studies with a between-subjects manipulation, participants were randomly assigned to conditions using the Qualtrics randomizer. All studies were conducted with the approval of [redacted for anonymous review] Institutional Review Board. For all studies, we report unstandardized (rather than standardized) effect sizes to make the results of our studies more interpretable and comparable across designs (Pek \& Flora, 2018). Unless otherwise stated, we employed 7-point scales for all outcome measures. Tables with estimated means depending on the condition for every study can be found in the Supplemental Materials. For all studies, we did not exclude participants based on questions presented after random assignment (e.g., attention or comprehension checks) to avoid compromising random assignment (Montgomery et al., 2018).

\section{Study 1}

\footnotetext{
${ }^{9}$ For Study 1, a sensitivity power analysis indicated that given a .05 alpha level (two-tailed), $90 \%$ power, and 100 participants per condition we could detect an effect size of $d=0.46$. For Study 2, we found that given a .05 alpha level (two-tailed), 90\% power, and 122 participants we could detect an effect size of $d_{z}=0.30$. For Studies 3 and 4, we found that given a .05 alpha level, $90 \%$ power, and 517 participants in total (per study) we could detect an effect size for the interaction effect of $f=0.14$. For Studies 5 and 6 , we found that given a .05 alpha level, 90\% power, and 300 participants in total (per study) we could detect an effect size for the omnibus test of $f=0.21$. For Study 7, we found that given a .05 alpha level, $90 \%$ power, and 600 participants in total (per study) we could detect an effect size for the omnibus test of $f=0.15$. For Study 8 , we found that given a .05 alpha level (two-tailed), 90\% power, and 200 participants we could detect an effect size of $d_{z}=0.23$. For Study 9, we found that given a .05 alpha level (two-tailed), $90 \%$ power, and 364 participants we could detect an effect size of $d_{\mathrm{z}}=$ 0.17 . Note: for Study 9 we collapse the two binary factors into a single binary factor to simplify the power analysis.
} 
DOES MAXIMIZING GOOD MAKE PEOPLE LOOK BAD?

In Study 1, we presented participants with the description of a person who exhibited either a deliberative or empathic decision approach to donating to charity (between-subjects). The information about the person's approach was provided by giving participants the person's fictitious response (which was presented as real) to a survey question. Upon seeing the survey response, participants evaluated the person's moral character, traits (empathy, integrity, reasonableness, and competence), motives (moral and pragmatic), authentic prosocial motivation, desirability as social partners, and trustworthiness. In studies using this scenario (i.e., Studies 1-4 and 7), we refer to the person being evaluated by participants as the respondent (in order to distinguish the person participants are evaluating from the participants themselves). We expected the moral character of deliberative respondents to be evaluated more negatively compared to empathic respondents, and we expected deliberative respondents to be perceived as lower in empathy (manipulation check) and integrity, but higher in reasonableness and competence. We anticipated deliberative respondents to be judged as less guided by moral motives and more by pragmatic motives, and we expected them to be rated as less guided by an authentic prosocial motivation, less desirable as social partners, and less trustworthy. We used a between-subjects design to remove carry-over effects and ameliorate potential demand effects (Bartels et al., 2015).

\section{Method}

Participants. We aimed to recruit 200 participants (100 per group). 200 participants completed our survey (102 Males, 95 Females, 2 Other, and 1 unreported, $M_{\text {age }}=35.30, S D_{\text {age }}$ $=10.59$, age range $=19-67)$. There were 99 participants in the deliberation condition and 101 in the empathy condition.

Procedure. To manipulate the perceived decision approach, participants evaluated a person's fictitious response (which was presented as real) to a survey question about how to select a charity (“If you were to donate, how would you select which charity to donate to?"). 
DOES MAXIMIZING GOOD MAKE PEOPLE LOOK BAD?

The response indicated either a deliberative ("I would use evidence to calculate which charity spends its donations most cost effectively, and donate to them") or an empathic approach ("I would try to put myself in the shoes of people who are going through difficult situations, and donate to a charity that helped them"). To conceal the purpose of the study and increase its realism, we told participants the question and response were selected at random from a survey on political attitudes conducted by the Pew Research Center. To reduce inferences based on the name and the gender of the respondent, we told participants that the name of the respondent was changed to preserve his or her identity, and that the respondent was named 'John'. To focus on evaluations of the decision approach, rather than on the outcomes of the donation, we made the donation decision hypothetical (i.e., how respondents would select a charity if they were to donate). After presenting the manipulation, we administered the measures. For Studies 1-7, the scenario remained on the screen while participants answered the measures to ensure that they did not forget the scenario. At the end of the study, we measured sociodemographic variables and exit questions.

Measures. For all measures, we asked participants to evaluate the survey respondent (that is, John). We measured moral character by asking participants to evaluate John on a 12item scale (Barasch et al., 2014) including both positive (moral, altruistic, sincere, pure, good, and nice) and negative (immoral, selfish, insincere, impure, bad, and mean; $1=$ Not at all, $7=$ Extremely) items $(\alpha=0.92)$. Negative items were reverse-scored. To measure character traits (Uhlmann et al., 2013), we asked participants to evaluate John's empathy (caring, warm, and empathic; $\alpha=0.91$ ), integrity (principled, honorable, and virtuous; $\alpha=0.82$ ), reasonableness (reasonable, effective, realistic, and rational; $\alpha=0.92$ ), and competence (competent, skilled, and proficient; $\alpha=0.92 ; 1=$ Not at all, $7=$ Extremely). We measured moral motives (Uhlmann et al., 2013) by asking participants whether John's approach was based on "genuine moral concern", “moral principle”, “a genuine moral stand”, "personal self-interest" 
DOES MAXIMIZING GOOD MAKE PEOPLE LOOK BAD?

(reverse-scored), "what was good for him personally" (reverse-scored), and "selfish reasons" (reverse-scored; $\alpha=0.79 ; 1=$ Definitely not, $7=$ Definitely yes). We measured pragmatic motives (Uhlmann et al., 2013) by asking participants whether John's approach was based on "what was reasonable", "what was rational", and on "a pragmatic stand" $(\alpha=0.67 ; 1=$ Definitely not, 7 = Definitely yes). We measured authentic prosocial motivation (Barasch et al., 2014) by asking participants whether John "sincerely cares about the recipient(s) of the donation", "wants to donate to benefit the recipient(s) of the donation" (1 = Strongly Disagree, 7 = Strongly Agree), and by asking "How authentic do you find John's approach?" $(1=$ Not at all authentic, 7 = Extremely authentic $)$ and "How suspicious are you of John's intentions?" (reverse-scored; $\alpha=0.83 ; 1=$ Not at all suspicious, $7=$ Extremely suspicious). We measured desirability as social partners by asking participants to rate the extent to which somebody like John would be a good person to have as a co-worker, neighbor, roommate, close friend, and romantic partner $(\alpha=0.90 ; 1=$ Not at all, $7=$ Extremely). We measured trustworthiness by asking “How trustworthy is John?" (1 = Extremely untrustworthy, $7=$ Extremely trustworthy). We included single item measures of empathy ("John feels for the recipient(s) of the donation") and concern ("John wants to help the recipient(s) of the donation"; 1 = Strongly Disagree, 7 = Strongly Agree). For measures with more than one item, we calculated a composite score by averaging the corresponding items (after reverse scoring items if necessary). We then measured sociodemographic variables (age, gender, race, born in the USA, education, income, political orientation, religiosity, and self-rank of social position) and three exit questions about participants' perception of the survey.

Before the study, we conducted a pilot of the manipulation $(N=50$; deliberation vs. empathy; between-subjects) in which we measured empathy ( $\alpha=0.92$; along with other character traits: integrity, reasonableness, and competence) and single item measures of empathy and concern. The measures were the same as the ones used in Study 1. As expected, 
DOES MAXIMIZING GOOD MAKE PEOPLE LOOK BAD?

empathic respondents were judged higher in empathy $(M=6.08, S D=1.09, n=24)$

compared to deliberative respondents $(M=5.08, S D=1.25, n=26), M_{\text {diff }}=1.01,95 \% \mathrm{CI}$

$[0.34,1.67], t(47.90)=3.04, p=.004$.

\section{Results}

We used two-sided unequal variances $t$-tests to examine differences in the conditions (using generalized least-squares) and calculated unstandardized mean differences (empathy minus deliberation) and 95\% confidence intervals around them. A positive mean difference indicates a higher score in the empathy condition than in the deliberation condition. Most analyses in this paper were conducted using the emmeans R package (version 1.3.0; Lenth, 2018).

As expected, the manipulation check showed that participants rated empathic respondents higher in empathy, compared to deliberative respondents, $M_{\text {diff }}=0.78,95 \% \mathrm{CI}$ $[0.46,1.09], t(189)=4.86, p<.001$. As predicted, deliberative respondents were rated lower in moral character, $M_{\text {diff }}=0.37,95 \%$ CI $[0.14,0.61], t(193)=3.10, p=.002$, but higher in reasonableness, $M_{\text {diff }}=-0.38,95 \%$ CI $[-0.66,-0.10], t(195)=-2.65, p=.009$, and competence, $M_{\text {diff }}=-0.49,95 \%$ CI [-0.77, -0.20$], t(194)=-3.35, p=.001$. As expected, deliberative respondents were evaluated as less guided by moral motives, $M_{\text {diff }}=0.53,95 \%$ CI $[0.24,0.82], t(194)=3.60, p<.001$, more guided by pragmatic motives, $M_{\text {diff }}=-0.45$, $95 \%$ CI $[-0.70,-0.19], t(197)=-3.43, p<.001$, and as less desirable as social partners, $M_{\text {diff }}=$ $0.41,95 \% \mathrm{CI}[0.09,0.73], t(197)=2.52, p=.013$. Contrary to expectations, we failed to find differences in integrity, $M_{\text {diff }}=-0.13,95 \%$ CI $[-0.41,0.14], t(195)=-0.95, p=.342$, authentic prosocial motivation, $M_{\text {diff }}=0.19,95 \% \mathrm{CI}[-0.10,0.47], t(198)=1.27, p=.207$, and trustworthiness, $M_{\text {diff }}=0.12,95 \%$ CI $[-0.16,0.41], t(198)=0.86, p=.391$. Since null results can be explained by the absence of an effect or insufficient statistical power (Lakens, Scheel, \& Isager 2018), we urge readers to check the confidence intervals of our null results to see 
DOES MAXIMIZING GOOD MAKE PEOPLE LOOK BAD?

which effects we cannot reject. For the null results in this study, we cannot reject many effects that could be deemed interesting.

\section{Discussion}

Compared to empathic respondents, deliberative respondents were evaluated lower in moral character, moral motives, and desirability as social partners. However, deliberative respondents were evaluated higher in reasonableness, competence, and pragmatic motives. These differences were found in the upper part of the scale (around 5-6 on 7-point scales), suggesting that despite relative differences between "deliberators" and "empathizers" both are probably evaluated positively in absolute terms.

Given that our manipulation was between-participants (i.e., participants only read one description of an empathic or deliberative respondent), judgments could change if both descriptions were presented simultaneously (Hsee et al., 1999). For instance, when evaluating both descriptions simultaneously, participants could evaluate deliberative respondents more positively if it becomes obvious that their approach leads to better outcomes. Thus, in Study 2 we asked participants to evaluate both approaches simultaneously.

\section{Study 2}

In this study, we tested the same hypotheses as Study 1 using a within-subjects design in which participants simultaneously evaluated two respondents: one who exhibited a deliberative approach to donating to charity and one who exhibited an empathic approach to donating to charity.

\section{Method}

Participants. We aimed to recruit 122 participants. 122 participants completed our survey (70 Males and 52 Females, $M_{\text {age }}=37.33, S D_{\text {age }}=11.96$, age range $=18-68$ ). 
DOES MAXIMIZING GOOD MAKE PEOPLE LOOK BAD?

Procedure. We adapted the scenario used in Study 1 to a within-subjects design, but made no other significant changes. Participants were presented with the survey responses of two respondents: one who exhibited a deliberative approach to donating to charity and one who exhibited an empathic approach to donating to charity. Participants evaluated these respondents simultaneously rather than one after the other. We randomized the order of the approaches (that is, in the same screen, which approach was presented and evaluated first or second), and the name of the respondents (that is, whether respondents were named John or David), in order to avoid creating a confound between the order of presentation or the name of the respondents and the approach.

Measures. The measures were similar to the ones used in the previous study. We report Cronbach's alpha separately for each condition. We measured moral character (deliberation: $\alpha=0.88$, empathy: $\alpha=0.89$ ), empathy (deliberation: $\alpha=0.92$, empathy: $\alpha=$ 0.86), integrity (deliberation: $\alpha=0.84$, empathy: $\alpha=0.88$ ), reasonableness (deliberation: $\alpha=$ 0.91, empathy: $\alpha=0.90$ ), competence (deliberation: $\alpha=0.95$, empathy: $\alpha=0.94$ ), moral motives (deliberation: $\alpha=0.74$, empathy: $\alpha=0.75$ ), pragmatic motives (deliberation: $\alpha=$ 0.81, empathy: $\alpha=0.87$ ), authentic prosocial motivation (deliberation: $\alpha=0.87$, empathy: $\alpha=$ 0.77), desirability as social partners (deliberation: $\alpha=0.93$, empathy: $\alpha=0.92$ ), trustworthiness, and single item measures of empathy and concern. For questions that contained the name of the respondent, we used male pronouns (he or his) instead of names to make them applicable to both respondents. We also measured the same sociodemographic variables and exit questions.

\section{Results}

We conducted two-sided paired sample $t$-tests (using linear mixed models) and calculated unstandardized mean differences (empathy minus deliberation) and 95\% 
DOES MAXIMIZING GOOD MAKE PEOPLE LOOK BAD?

confidence intervals around them. A positive mean difference suggests a higher score in the empathy than in the deliberation condition.

As predicted, the manipulation check showed that participants rated empathic respondents higher in empathy than deliberative respondents, $M_{\text {diff }}=1.25,95 \%$ CI $[0.98$, $1.51], t(121)=9.23, p<.001$. As expected, "deliberators" were rated lower in moral character, $M_{\text {diff }}=0.42,95 \% \mathrm{CI}[0.27,0.56], t(121)=5.62, p<.001$, and integrity, $M_{\text {diff }}=$ $0.26,95 \%$ CI $[0.05,0.47], t(121)=2.48, p=.015$, but higher in reasonableness, $M_{\text {diff }}=-0.95$, $95 \%$ CI $[-1.22,-0.68], t(121)=-6.94, p<.001$, and competence, $M_{\text {diff }}=-0.85,95 \%$ CI $[-1.11$, -0.59], $t(121)=-6.45, p<.001$. As predicted, deliberative respondents were perceived as less guided by moral motives, $M_{\text {diff }}=0.69,95 \%$ CI $[0.49,0.90], t(121)=6.59, p<.001$, more guided by pragmatic motives, $M_{\text {diff }}=-1.55,95 \%$ CI $[-1.88,-1.21], t(121)=-9.08, p<.001$, less guided by authentic prosocial motivation, $M_{\text {diff }}=0.49,95 \% \mathrm{CI}[0.26,0.71], t(121)=$ $4.21, p<.001$, and less desirable as social partners, $M_{\text {diff }}=0.52,95 \%$ CI $[0.28,0.76], t(121)=$ 4.33, $p<.001$. However, we failed to observe an effect on trustworthiness, $M_{\text {diff }}=0.24,95 \%$ CI $[-0.002,0.48], t(121)=1.97, p=.052$, though we cannot reject many effects that could be deemed interesting (see confidence interval).

\section{Discussion}

These results strongly support our hypotheses. All results found in the previous study were replicated, and we also found support for predictions not supported in the previous study. Moreover, effect sizes were larger compared to the previous study. These stronger results could be due to greater statistical power associated with within-subjects designs (Lakens, 2016), and simultaneous evaluation eliciting the effects of interest more strongly by allowing a comparison between the approaches. However, demand characteristics may also promote compliance with our hypotheses. 
DOES MAXIMIZING GOOD MAKE PEOPLE LOOK BAD?

Taken together, Studies 1 and 2 suggest that deliberative respondents are rated less positively on morality and partner desirability measures, but more positively on pragmatism measures, than empathic respondents. These results were found when the decision approaches were evaluated in isolation and simultaneously, suggesting these results are not contingent on a particular form of evaluation (Bartels et al., 2015). However, one limitation with previous studies is that respondents had stereotypically male names. To attempt to reduce the impact gender may have on inferences, we told participants that the name of the respondent (or respondents) was changed to preserve his or her identity (or identities). Yet, participants could have made gender inferences based on the names presented. If so, whether these results extend to female respondents remains unclear. Additionally, though we sought to use names that, aside from gender, were neutral with respect to other characteristics that may influence responses, the chosen names could have influenced responses in unknown ways (Simonsohn, 2015; Wells \& Windschitl, 1999). We address both shortcomings in the next study.

\section{Study 3}

One potential moderator of the effect of the decision approach towards donations on evaluations is the gender of the person being evaluated, given the stronger normative expectation for women (compared to men) to exhibit communality and warmth (Connor et al., 2017; Eagly et al., 2019). If so, women could be penalized more strongly (compared to men) for displaying a cold and deliberative approach (put differently, for exhibiting behaviors that violate stereotypical gender expectations). Alternatively, both men and women could be equally penalized for not expressing empathy, if identifying desirable social partners is a concern that applies equally across genders. In this study, participants evaluated a male or female survey respondent exhibiting an empathic or deliberative approach to donating to 
DOES MAXIMIZING GOOD MAKE PEOPLE LOOK BAD?

charity. The study had a 2 (decision approach: empathy vs. deliberation) x 2 (gender: male vs. female) between-subjects design. Our hypotheses were similar to those of Study 1 but, in addition, we did not expect the effect of decision approach to depend on the gender of the person being evaluated. Despite different stereotypical gender expectations for men and women (Connor et al., 2017; Eagly et al., 2019), we suspect there is an equally strong expectation across genders to act empathically when helping others. Thus, we predicted a non-significant interaction between decision approach and gender, and a main effect of decision approach.

\section{Method}

Participants. We aimed to recruit 517 participants. 516 participants completed our survey (241 Males, 274 Females, and 1 Other, $M_{\text {age }}=36.84, S D_{\text {age }}=12.05$, age range $=19$ 77). 12 out of 516 participants (2\%) failed a simple attention check. We used the same attention check in Studies 4-6. There were 131 participants in the female-deliberation condition, 127 participants in the female-empathy condition, 128 participants in the maledeliberation condition, and 130 participants in the male-empathy condition.

Procedure. We manipulated decision approach using the same procedure as Study 1, and we manipulated gender by describing the respondent using either male or female pronouns (e.g., "he" or "she"). We explained that "The name of the respondent will not be presented to preserve his or her identity. Only the sex of the respondent will be shown." ${ }^{10} \mathrm{We}$ used pronouns rather than names, given that names are associated with sociodemographic characteristics, such as age, race, and socioeconomic status, that may confound the gender manipulation (Simonsohn, 2015; Wells \& Windschitl, 1999). For instance, the names 'Elmer'

\footnotetext{
${ }^{10}$ Although we mentioned the term 'sex' once, our intent was to manipulate gender (which we primarily did through using male or female pronouns and mentioning the respondent was a man/woman). Sex and gender are distinct from one another, and it is possible that conflating the two influenced our results. However, we believe this is unlikely since we only mentioned it once (whereas pronouns were used throughout), and the terms are often used interchangeably in colloquial discourse.
} 
DOES MAXIMIZING GOOD MAKE PEOPLE LOOK BAD?

and 'Mildred' could lead participants to infer respondents are older, compared to the names 'Aiden' and 'Lily' (Silver \& McCann, 2014). Since one potential shortcoming of manipulating gender at the construct level (as opposed to using concrete instances) is reduced saliency (Wells \& Windschitl, 1999), we made the gender more explicit by including a reminder below the manipulation ("Think about the man/woman who answered this question").

Measures. The measures were similar to those of Study 1 with some differences. First, we adjusted the wording from names to pronouns. Second, we did not measure integrity, trustworthiness, and single item measures of empathy and concern. Third, we included additional exploratory measures.

We measured moral character ( $\alpha=0.89$ ), character traits (empathy, $\alpha=0.91$; reasonableness, $\alpha=0.91$, and competence, $\alpha=0.92$ ), motives (moral, $\alpha=0.77$, and pragmatic, $\alpha=0.80)$, authentic prosocial motivation $(\alpha=0.82)$, and desirability as social partners $(\alpha=0.90)$. For exploratory purposes, we measured anticipated negative judgment of one's perspective on charity ("Imagine this person evaluates your perspective on charity. How would he/she judge your thinking about charity?"; 1 = Very negative, 7 = Very positive), wastefulness and cost-effectiveness of the approach ("How wasteful/cost-effective is his/her approach to donations?"; 1 = Not at all, 7 = Extremely), two items regarding appropriateness of emotional expressions depending on gender ("It is appropriate for women to be more emotional than men", "It is appropriate for men to be more cold than women"; 1 = Definitely not, 7 = Definitely yes $)$, and the 13 -item Person-Thing Orientation scale $(1=$ not at all, $5=$ extremely; Graziano et al., 2011). We included a simple attention check ("Select the number 2 so that we know you are paying attention"; 7-point scale) and placed it after the main measures to avoid prompting systematic thinking (Hauser \& Schwarz, 2015). We measured similar sociodemographics to Study 1, except that we did not measure whether people were 
DOES MAXIMIZING GOOD MAKE PEOPLE LOOK BAD?

born in the USA or self-rank of social position, and only used one instead of two items to measure political orientation and religiosity. We used similar exit questions to Study 1.

\section{Results}

We examined how scores on the measures varied depending on the decision approach (empathy vs. deliberation), gender of respondent (male vs. female), and their interaction. We estimated main effects and interactions. Main effects for decision approach (empathy conditions minus deliberation conditions) and gender (male conditions minus female conditions) were calculated using unweighted marginal means. We calculated unstandardized mean differences and $95 \%$ confidence intervals around them.

As predicted, the manipulation check showed that empathic respondents were rated higher in empathy, compared to deliberative respondents, $b=0.83,95 \%$ CI $[0.65,1.00]$, $t(512)=9.11, p<.001$. As expected, we failed to find interaction effects: empathy: $b=0.33$, $95 \%$ CI $[-0.03,0.68], t(512)=1.80, p=.072$; moral character: $b=-0.05,95 \%$ CI $[-0.32$, $0.23], t(512)=-0.34, p=.738$; reasonableness: $b=0.18,95 \%$ CI $[-0.14,0.50], t(512)=1.12$, $p=.265$; competence: $b=0.02,95 \%$ CI $[-0.34,0.37], t(512)=0.08, p=.934$; moral motives: $b=0.17,95 \% \mathrm{CI}[-0.19,0.53], t(512)=0.92, p=.356$; pragmatic motives: $b=0.25,95 \% \mathrm{CI}$ $[-0.12,0.63], t(512)=1.33, p=.185 ;$ desirability as social partners: $b=0.14,95 \%$ CI $[-0.26$, $0.53], t(512)=0.69, p=.492$, and authentic prosocial motivation: $b=-0.19,95 \%$ CI [-0.53, $0.15], t(512)=-1.10, p=.271$.

Though we did not have specific predictions, we failed to find main effects of gender: empathy: $b=-0.05,95 \%$ CI $[-0.23,0.13], t(512)=-0.57, p=.569$; moral character: $b=-0.02$, $95 \%$ CI $[-0.16,0.11], t(512)=-0.35, p=.729$; reasonableness: $b=0.03,95 \%$ CI $[-0.13$, $0.19], t(512)=0.36, p=.716$; competence: $b=-0.02,95 \%$ CI $[-0.20,0.16], t(512)=-0.18, p$ $=.854$; moral motives: $b=-0.05,95 \%$ CI $[-0.23,0.13], t(512)=-0.53, p=.596$; pragmatic motives: $b=0.13,95 \%$ CI $[-0.06,0.32], t(512)=1.35, p=.177$; desirability as social 
DOES MAXIMIZING GOOD MAKE PEOPLE LOOK BAD?

partners: $b=0.02,95 \%$ CI $[-0.17,0.22], t(512)=0.23, p=.816$, and authentic prosocial motivation: $b=0.04,95 \%$ CI $[-0.13,0.21], t(512)=0.42, p=.675$. Despite failing to find interaction or main effects of gender, we cannot reject many effects that could be deemed interesting (see confidence intervals).

Regarding the main effects of decision approach we found, as expected, that deliberative respondents were rated lower in moral character, $b=0.30,95 \% \mathrm{CI}[0.17,0.44]$, $t(512)=4.38, p<.001$, though higher in reasonableness, $b=-0.53,95 \%$ CI $[-0.69,-0.37]$, $t(512)=-6.51, p<.001$, and competence, $b=-0.56,95 \%$ CI $[-0.74,-0.38], t(512)=-6.14, p<$ .001 . As predicted, "deliberators" were perceived as less guided by moral motives, $b=0.35$, $95 \%$ CI $[0.17,0.53], t(512)=3.83, p<.001$, more guided by pragmatic motives, $b=-0.82$, $95 \%$ CI $[-1.00,-0.63], t(512)=-8.56, p<.001$, and less desirable as social partners, $b=0.41$, $95 \%$ CI $[0.22,0.61], t(512)=4.14, p<.001$. Unexpectedly, we failed to find an effect of decision approach on authentic prosocial motivation, $b=0.10,95 \% \mathrm{CI}[-0.07,0.27], t(512)=$ $1.16, p=.245$.

\section{Discussion}

We found support for most predictions of the effect of decision approach, and we did not find evidence that these effects depend on the gender of the person being evaluated. These findings suggest that our previous results may extend across genders and are not contingent on the specific names used in Studies 1 and 2.

In Study 4, we test whether the stakes of the donation affect the evaluations of respondents, since participants could evaluate a respondent's approach to donations differently depending on the amount of money involved. Prior research found that people who make consequentialist decisions (i.e., a hospital administrator who spent large amounts of money buying new equipment rather than saving a child) were viewed as having worse moral character but were viewed as better leaders, raising the possibility that people prefer 
DOES MAXIMIZING GOOD MAKE PEOPLE LOOK BAD?

leaders who have a suppressed sense of empathy and favor decisions that maximize outcomes (Uhlmann et al., 2013). In fact, when people are asked to imagine taking a role of responsibility (i.e., medical center president) they allocate resources more cost-effectively than when they decide as regular donors (Berman et al., 2018).

Since donors allocating large sums of money may be perceived to be in a leadership position and have a role of responsibility (given that their decisions have important societal consequences) people may therefore expect them to avoid relying on empathy and, instead, donate based on a deliberative approach. Alternatively, people may be more sensitive to outcomes than signaling considerations when large sums of money are involved. Either way, donors who deliberate may therefore be less derogated on morality and partner desirability measures (compared to donors who empathize) when donating very large sums of money given that their approach matches the situational demands. For the same reason, donors who deliberate may be evaluated more positively on pragmatism measures when donating very large sums of money.

\section{Study 4}

In this study, we examined the moderating role of the stakes of the donation. In particular, deliberative respondents (compared to empathic respondents) may be evaluated less negatively on morality and partner desirability measures and more positively on pragmatism measures when the consequences of donating efficiently are greater (that is, when there is more money being donated), since donors may be expected to donate more pragmatically when the stakes are higher. To test this, we asked participants to evaluate a respondent who exhibited either a deliberative or empathic approach to donating a very large (100 million dollars) or small (10 dollars) amount of money to charity. The study had a 2 (decision approach: empathy vs. deliberation) x 2 (stakes: low vs. high) between-subjects 
DOES MAXIMIZING GOOD MAKE PEOPLE LOOK BAD?

design. We expected moral character evaluations of deliberative respondents to be more negative than empathic respondents in low stakes situations, but we anticipated this effect to be attenuated in high stakes situations. Moreover, we expected deliberative respondents to be rated as less guided by moral motives, less guided by an authentic prosocial motivation, and less desirable as social partners in low stakes situations, though we anticipated these effects to be attenuated in high stakes situations. In addition, we expected deliberative respondents to be judged as more reasonable and competent, and more guided by pragmatic motives in low stakes situations, but we expected these effects to be stronger in high stakes situations. Thus, for these analyses we predicted an interaction between the decision approach and the stakes. As manipulation checks, we examined whether deliberative respondents were rated lower in empathy compared to empathic respondents, and whether the high stakes decisions were perceived to be more important than the low stakes decisions.

\section{Method}

Participants. We aimed to recruit 517 participants. 521 participants completed our survey (231 Males, 287 Females, 2 Other, and 1 unreported, $M_{\mathrm{age}}=35.97, S D_{\mathrm{age}}=11.51$, age range $=19-81) .10$ out of 521 participants $(2 \%)$ failed the attention check and 83 out of 521 participants (16\%) failed a comprehension check of the manipulation. There were 130 participants in the high stakes-deliberation condition, 131 participants in the high stakesempathy condition, 132 participants in the low stakes-deliberation condition, and 128 participants in the low stakes-empathy condition.

Procedure. To manipulate the decision approach, we used the manipulation employed in Study 1, and to manipulate the stakes of the donation, we changed the amount of money of the hypothetical donation. In the high stakes condition, the respondent considered how they would select a charity/charities to donate 100 million dollars, whereas in the low stakes condition, the respondent considered how they would select a charity/charities to 
DOES MAXIMIZING GOOD MAKE PEOPLE LOOK BAD?

donate 10 dollars. We made the difference between the stakes conditions dramatic because participants were not able to compare the donation amounts (given the between-subjects design), but instead relied on their notion of what constitutes a large or small donation. In the high stakes condition, participants were told that the respondent was asked: "If you were to donate a very large sum of money (e.g., \$100 million dollars), how would you select which charity/charities to donate to? For the purpose of the question, please imagine that you have this amount of money and are going to donate it to charity." In the low stakes condition, we only modified the amount to "a small amount of money (e.g., \$10 dollars)". Compared to Study 1 , we changed the framing of the question (and response) from donating to a single charity to multiple charities, because donating large amounts of money to a single charity could be deemed inefficient (e.g., a charity may not have the capacity to handle such amounts) and we wanted to avoid this potential confound.

Measures. The measures were similar to the ones used in Study 1, though we did not include measures of integrity, trustworthiness, and single item measures of empathy and concern. We also included other measures for exploratory purposes. We measured moral character $(\alpha=0.91$ ), character traits (empathy, $\alpha=0.91$; reasonableness, $\alpha=0.91$, and competence, $\alpha=0.92$ ), motives (moral, $\alpha=0.79$, and pragmatic, $\alpha=0.73$ ), authentic prosocial motivation $(\alpha=0.84)$, and desirability as social partners $(\alpha=0.90)$. As a manipulation check of the stakes manipulation we included two items: "How important/consequential is the decision that John is being asked to consider?" $(\alpha=0.76 ; 1=$ Not at all, $7=$ Extremely). For exploratory purposes, we measured perceptions of wealth ("How wealthy do you think is John?"; 1 = Very poor, 7 = Very rich), norms about the required level of carefulness of the decision ("How carefully should John think about where to donate in this situation?"; 1 = Not at all, 7 = Extremely), carefulness ("How careful was John about this decision?" and "Was John insufficiently careful in thinking about this 
DOES MAXIMIZING GOOD MAKE PEOPLE LOOK BAD?

decision?", reverse-scored; 1 = Not at all, 7 = Extremely), wastefulness and cost-effectiveness of the donation ("How wasteful/cost--effective is John's donation?"; 1 = Not at all, $7=$ Extremely), and likelihood of donating in the future ("How likely is it that John will donate in the future?" and "How likely is it that John will repeatedly donate over time?"). After the main measures, we included an attention check followed by a comprehension check (to verify whether participants understood the hypothetical nature of the stakes manipulation). We included the same sociodemographics and exit questions as Study 3.

\section{Results}

We examined how scores on the measures varied depending on the decision approach (empathy vs. deliberation), the stakes (low vs. high), and their interaction. We calculated main effects and interactions. Main effects for the decision approach (empathy conditions minus deliberation conditions) and the stakes (low conditions minus high conditions) were calculated using unweighted marginal means. We calculated unstandardized mean differences and $95 \%$ confidence intervals around them.

As expected, the manipulation checks showed that empathic respondents were rated higher in empathy compared to deliberative respondents, $b=0.89,95 \%$ CI $[0.69,1.08]$, $t(517)=8.89, p<.001$, and the high stakes decision was perceived to be more important compared to the low stakes decision, $b=-1.34,95 \%$ CI $[-1.58,-1.11], t(517)=-11.16, p<$ .001. Contrary to expectations, the stakes failed to moderate the effects of decision approach (that is, there were no significant interactions): moral character: $b=0.09,95 \%$ CI $[-0.20$, 0.39], $t(517)=0.60, p=.546$; reasonableness: $b=0.09,95 \%$ CI $[-0.27,0.44], t(517)=0.47, p$ $=.638$; competence: $b=0.15,95 \%$ CI $[-0.24,0.55], t(517)=0.77, p=.441$; moral motives: $b$ $=0.06,95 \% \mathrm{CI}[-0.32,0.43], t(517)=0.29, p=.772$; pragmatic motives: $b=0.02,95 \% \mathrm{CI}[-$ $0.35,0.39], t(517)=0.09, p=.927$; desirability as social partners: $b=0.30,95 \%$ CI $[-0.12$, $0.73], t(517)=1.39, p=.164$, and authentic prosocial motivation: $b=0.21,95 \%$ CI [-0.14, 
DOES MAXIMIZING GOOD MAKE PEOPLE LOOK BAD?

$0.55], t(517)=1.16, p=.246$. As expected, there were no interactions regarding empathy, $b=$ $0.19,95 \%$ CI $[-0.20,0.59], t(517)=0.98, p=.330$, or perceived importance, $b=0.34,95 \%$ CI $[-0.13,0.81], t(517)=1.41, p=.160$.

Although we did not have particular predictions, we also failed to observe main effects of stakes: moral character: $b=-0.05,95 \%$ CI $[-0.20,0.10], t(517)=-0.68, p=.497$; empathy: $b=-0.16,95 \%$ CI $[-0.36,0.04], t(517)=-1.59, p=.112$; reasonableness: $b=0.03$, $95 \%$ CI $[-0.15,0.20], t(517)=0.30, p=.761$; competence: $b=0.02,95 \%$ CI $[-0.18,0.22]$, $t(517)=0.20, p=.845$; moral motives: $b=-0.04,95 \%$ CI $[-0.23,0.15], t(517)=-0.42, p=$ .676 ; pragmatic motives: $b=0.07,95 \%$ CI $[-0.11,0.26], t(517)=0.76, p=.450$; desirability as social partners: $b=-0.07,95 \%$ CI $[-0.28,0.14], t(517)=-0.67, p=.502$, and authentic prosocial motivation: $b=-0.06,95 \%$ CI $[-0.23,0.12], t(517)=-0.62, p=.533$. Although we did not find interaction effects or main effects of stakes, we cannot reject many effects that could be deemed interesting (see confidence intervals).

We found main effects of decision approach for all measures (except the effect on authentic prosocial motivation). Participants evaluated the moral character of deliberative respondents more negatively, compared to empathic respondents, $b=0.40,95 \%$ CI $[0.26$, $0.55], t(517)=5.38, p<.001$, though deliberative respondents were perceived as more reasonable, $b=-0.51,95 \% \mathrm{CI}[-0.69,-0.34], t(517)=-5.70, p<.001$, and competent, $b=-$ $0.60,95 \%$ CI $[-0.80,-0.41], t(517)=-6.02, p<.001$. Deliberative respondents were also perceived as less guided by moral motives, $b=0.48,95 \%$ CI $[0.29,0.66], t(517)=5.04, p<$ .001 , more guided by pragmatic motives, $b=-0.72,95 \%$ CI $[-0.90,-0.53], t(517)=-7.67, p<$ .001 , and less desirable as social partners, $b=0.46,95 \%$ CI $[0.25,0.68], t(517)=4.30, p<$ .001 . We failed to find an effect on authentic prosocial motivation, $b=0.13,95 \%$ CI [-0.04, $0.31], t(517)=1.51, p=.131$.

\section{Discussion}


DOES MAXIMIZING GOOD MAKE PEOPLE LOOK BAD?

In line with previous results, deliberative respondents were evaluated less positively on moral and partner desirability measures, but they were evaluated more positively on pragmatism measures. Unexpectedly, these results failed to be moderated by the stakes of the donation, despite the stakes manipulation check succeeding and participants indicating that high stakes respondents should think more carefully about where to donate than low stakes respondents, $b=-0.86,95 \% \mathrm{CI}[-1.07,-0.66], t(517)=-8.26, p<.001$. Participants also recognized which approach is more efficient, given that they rated deliberative respondents lower in wastefulness, $b=0.28,95 \%$ CI [0.06, 0.49], $t(517)=2.52, p=.012$, and higher in cost-effectiveness, $b=-1.36,95 \%$ CI [-1.59, -1.12], $t(517)=-11.37, p<.001$.

A few limitations are worth considering. First, participants rated high stakes respondents as more wealthy than low stakes respondents, $b=-1.02,95 \%$ CI [-1.21, -0.83$]$, $t(517)=-10.45, p<.001$, despite specifying that respondents imagined having these amounts of money to avoid this confound. Second, since the stakes manipulation involved the hypothetical possibility of donating different sums of money, it is unclear whether these results extend to scenarios in which people actually donate these amounts of money. Third, the power of studies testing interaction effects (like Studies 3 and 4) depends on the form of the interaction and, for these studies, we can therefore not reject less extreme interaction effects that may be interesting and detectable with greater power (Giner-Sorolla, 2018; Simonsohn, 2014). We urge readers to check the confidence intervals of our null effects to see which effects we cannot reject.

A broader limitation applying to all previous studies is the use of the same scenario (i.e., evaluating a person's response to a survey). Finding similar results using a different scenario would increase our confidence in our hypotheses (Lykken, 1968). Thus, in the next study we tested an alternative scenario. 
DOES MAXIMIZING GOOD MAKE PEOPLE LOOK BAD?

\section{Study 5}

In this study, we tested a different scenario in which a person (“John") is asked by a charity fundraiser whether he would donate to help Rokia, an extremely poor 7-year-old girl from Africa. In the deliberation condition, John considers the cost-effectiveness of the charity and after asking the fundraiser about the relevant statistics of the program and learning that the data suggests that the charity is the most cost-effective, John donates to help Rokia. In the empathy condition, John is deeply moved by Rokia's situation and after imagining how his donation could help her, John donates to help Rokia. We also included a condition in which John did not donate. Thus, the study had three conditions: empathy, deliberation, and nodonation (between-subjects). After reading the scenario, participants evaluated John. Our predictions regarding empathy and deliberation were similar to those of Study 1.

Additionally, we expected the comparison between no-donation and deliberation to fail to be different on measures related to morality and partner desirability (moral character, empathy, moral motives, trustworthiness, and desirability as social partners), but expected the nodonation condition to have lower scores compared to the empathy condition on these measures. Moreover, we expected the comparison between no-donation and empathy to fail to be different on measures related to pragmatism (reasonableness, competence, and pragmatic motives), but expected the no-donation condition to have lower scores than the deliberation condition on these measures.

\section{Method}

Participants. We aimed to recruit 300 participants (100 per condition). 300 participants completed our survey (134 Males, 165 Females, and 1 Other, $M_{\text {age }}=37.44, S D_{\text {age }}$ $=12.94$, age range $=18-80) .3$ out of 300 participants $(1 \%)$ failed the attention check. There were 100 participants in the empathy condition, 101 participants in the deliberation condition, and 99 participants in the no-donation condition. 
DOES MAXIMIZING GOOD MAKE PEOPLE LOOK BAD?

Procedure. Participants considered a scenario in which John was approached by a charity fundraiser and was asked whether he would be interested in donating to help Rokia, a 7-year-old girl from Mali, Africa who was desperately poor and faced the threat of severe hunger or even starvation. The charity fundraiser showed John a picture of Rokia (also presented to participants) and then asked John whether he would be interested in supporting her. The scenario was adapted from research on the identifiable victim effect (e.g., Small et al., 2007). Across conditions, participants were presented with the general scenario and only the potential donor's actions differed depending on the condition. In the deliberation condition, participants read that "John thought that donating to help Rokia might not be the most cost--effective way to use his money and that maybe he should donate to a charity doing something more cost-effective instead. He asked the charity fundraiser about the relevant statistics of the program and since the data suggested this charity was the most cost--effective John donated to the charity." In the empathy condition, participants read that "John was deeply moved by Rokia's situation and about how terrible her situation must be for her. After hearing about her tragic story and imagining how his donation could help her John donated to the charity." In both conditions John donates to Rokia, but he uses a different decision approach in each. Whereas in previous studies participants rated the respondent based on their thinking about a hypothetical donation decision, participants in the current study rated John based on his thinking about a real donation decision, in order to examine the generality of the results. To keep the consequences of the donation similar, we held the supported cause constant across the deliberation and empathy conditions. We also included a no-donation condition to examine how donors are evaluated relative to non-donors. In the no-donation condition, we stated that "John was not interested in donating and, thus, did not donate to the charity." 
DOES MAXIMIZING GOOD MAKE PEOPLE LOOK BAD?

Measures. The measures were similar to the ones used in Study 1, except we excluded integrity and single item measures of empathy and concern. Additionally, we changed the wording of questions to ask about the person's decision rather than their approach. We measured moral character $(\alpha=0.96)$, character traits (empathy, $\alpha=0.98$; reasonableness, $\alpha=0.94$, and competence, $\alpha=0.92$ ), motives (moral, $\alpha=0.89$, and pragmatic, $\alpha=0.89)$, authentic prosocial motivation $(\alpha=0.85)$, desirability as social partners $(\alpha=0.94)$, and trustworthiness. We did not measure authentic prosocial motivation in the nodonation condition because John did not engage in a prosocial act. After the main measures, we included a question to verify whether participants were moved by Rokia's situation (“How moving do you find Rokia's situation?"; 1 = Not at all, 7 = Extremely), two exploratory open questions (“Does anything seem negative about John's way of thinking/feeling?" and "Why do you think John thinks/feels the way he does?"), and an attention check. We included the same sociodemographic and similar exit questions as Study 3.

\section{Results}

We examined overall differences in the measures depending on the condition (i.e., omnibus tests), and pairwise comparisons (using the Holm adjustment) to examine specific group differences: "deliberation minus no-donation", "empathy minus no-donation", and “empathy minus deliberation". We calculated unstandardized mean differences and computed 95\% confidence intervals around them (only $p$ values were adjusted using the Holm adjustment, confidence intervals were not adjusted). Since we did not measure authentic prosocial motivation in the no-donation condition, we compared the deliberative and empathic conditions using two-sided unequal variances $t$-tests (employing generalized leastsquares). To check whether the scenario triggered empathy, we conducted a one sample $t$-test 
DOES MAXIMIZING GOOD MAKE PEOPLE LOOK BAD?

(one-sided) on empathy felt for Rokia to examine whether it was significantly higher than the scale midpoint (4).

All omnibus tests were significant $(p<.001)$, but since our interest lies in group comparisons we focus on these. As expected, the manipulation check showed that empathic donors were rated higher in empathy compared to deliberative donors, $M_{\text {diff }}=0.60,95 \% \mathrm{CI}$ $[0.27,0.92], t(297)=3.60, p<.001$. Additionally, participants appeared to be moved by Rokia's situation, since the mean empathy felt for Rokia was higher than the midpoint, $M=$ $5.35,95 \%$ CI [5.20, Inf], $t(299)=15.47, p<.001$.

Most predictions regarding deliberative and empathic donors were supported. As expected, deliberative donors (compared to empathic donors) were evaluated less positively on moral character, $M_{\text {diff }}=0.27,95 \%$ CI $[0.02,0.52], t(297)=2.11, p=.036$, but were perceived as more reasonable, $M_{\text {diff }}=-0.69,95 \%$ CI $[-1.01,-0.36], t(297)=-4.19, p<.001$, and competent, $M_{\text {diff }}=-0.56,95 \%$ CI $[-0.88,-0.25], t(297)=-3.57, p<.001$. As predicted, deliberative donors (compared to empathic donors) were perceived as more guided by pragmatic motives, $M_{\text {diff }}=-1.05,95 \%$ CI $[-1.39,-0.70], t(297)=-5.99, p<.001$, less guided by authentic prosocial motivation, $M_{\text {diff }}=0.63,95 \%$ CI $[0.32,0.94], t(180)=4.00, p<.001$, and less desirable as social partners, $M_{\text {diff }}=0.55,95 \%$ CI $[0.21,0.90], t(297)=3.17, p=.002$. Unexpectedly, we found no differences between empathic and deliberative donors regarding moral motives, $M_{\text {diff }}=0.29,95 \%$ CI $[-0.01,0.58], t(297)=1.91, p=.057$, and trustworthiness, $M_{\text {diff }}=-0.07,95 \% \mathrm{CI}[-0.36,0.23], t(297)=-0.44, p=.663$, though for moral motives most effects that we cannot rule out would support our hypothesis.

Our findings regarding non-donors were mixed. As expected, non-donors were rated lower than empathic donors on morality and partner desirability measures (moral character: $M_{\text {diff }}=2.14,95 \%$ CI $[1.89,2.40], t(297)=16.62, p<.001$, empathy: $M_{\text {diff }}=3.09,95 \%$ CI $[2.76,3.42], t(297)=18.54, p<.001$, moral motives: $M_{\text {diff }}=2.49,95 \%$ CI $[2.19,2.78], t(297)$ 
DOES MAXIMIZING GOOD MAKE PEOPLE LOOK BAD?

$=16.51, p<.001$, trustworthiness: $M_{\text {diff }}=1.30,95 \%$ CI $[1.00,1.59], t(297)=8.66, p<.001$, and desirability as social partners: $M_{\text {diff }}=2.21,95 \%$ CI $\left.[1.87,2.56], t(297)=12.61, p<.001\right)$, and non-donors were rated lower than deliberative donors on pragmatism measures (reasonableness: $M_{\text {diff }}=2.05,95 \%$ CI $[1.72,2.37], t(297)=12.47, p<.001$, competence: $M_{\text {diff }}$ $=1.64,95 \% \mathrm{CI}[1.33,1.95], t(297)=10.33, p<.001$, and pragmatic motives: $M_{\text {diff }}=1.71$, $95 \%$ CI $[1.36,2.05], t(297)=9.75, p<.001)$. Although we expected to fail to find differences between non-donors and deliberative donors, on morality and partner desirability measures, non-donors were rated lower than deliberative donors: moral character: $M_{\text {diff }}=1.87,95 \% \mathrm{CI}$ $[1.62,2.13], t(297)=14.56, p<.001$, empathy: $M_{\text {diff }}=2.49,95 \%$ CI $[2.17,2.82], t(297)=$ $14.99, p<.001$, moral motives: $M_{\text {diff }}=2.20,95 \%$ CI $[1.90,2.50], t(297)=14.65, p<.001$, trustworthiness: $M_{\text {diff }}=1.36,95 \%$ CI $[1.07,1.66], t(297)=9.12, p<.001$, and desirability as social partners: $M_{\text {diff }}=1.66,95 \%$ CI $[1.31,2.00], t(297)=9.47, p<.001$. Moreover, though we expected to fail to find differences between non-donors and empathic donors on pragmatism measures, non-donors were rated lower than empathic donors: reasonableness: $M_{\text {diff }}=1.36,95 \%$ CI $[1.04,1.68], t(297)=8.27, p<.001$, competence: $M_{\text {diff }}=1.07,95 \%$ CI $[0.76,1.39], t(297)=6.75, p<.001$, and pragmatic motives: $M_{\text {diff }}=0.66,95 \%$ CI $[0.32$, $1.01], t(297)=3.76, p<.001$.

\section{Discussion}

Using a new scenario in donation contexts, we replicated most of our previous results regarding perceptions of deliberative and empathic donors (only failing to find differences in moral motives and trustworthiness), strengthening our confidence in our hypotheses (Lykken, 1968). Furthermore, non-donors were evaluated more negatively than both empathic and deliberative donors (with non-donors rated either close to or below the scale midpoint, whereas empathic and deliberative donors rated above the scale midpoint). Contrary to our predictions, non-donors were rated lower than deliberative donors on morality and partner 
DOES MAXIMIZING GOOD MAKE PEOPLE LOOK BAD?

desirability measures, and non-donors were evaluated lower than empathic donors on pragmatism measures. Thus, compared to what we expected, non-donors were evaluated more negatively, perhaps because refusing to donate when prompted to do so signals a reluctance to act prosocially despite situational pressure to do so, which leads to much more negative evaluations.

Another limitation is that previous studies manipulated decision approach by presenting empathy and deliberation as discrete categories. However, in reality, the relationship between empathy and deliberation is more complicated (Helion \& Pizarro, 2015). People do not simply engage in discrete instances of empathy and deliberation, but more commonly experience varying degrees of both empathy and deliberation and may experience dynamic interactions between them. Examining some of these cases helps relax the unrealistic assumption that people only empathize or deliberate. In addition, examining instances that involve both empathy and deliberation may hint at strategies to reduce the reputational costs of making deliberative decisions, since people may not derogate donors who deliberate as long as they have intact emotional responses. Thus, in our next study we examined evaluations of donors who initially empathized but then overcame their empathic reaction and deliberated.

\section{Study 6}

In this study, we examined evaluations of donors who initially empathize but then also deliberate. We employed the scenario used in the previous study (i.e., donating to help a child in Africa). Participants considered the scenario of a deliberative or empathic donor, or a donor who initially empathized and then deliberated. We did not examine donors who initially deliberate but then empathize since these cases seem rare (perhaps because, for most people, empathizing is more intuitive than deliberating in response to others in need). The 
DOES MAXIMIZING GOOD MAKE PEOPLE LOOK BAD?

study had three conditions: empathy, deliberation, and mixed (i.e., the donor first empathized and then deliberated). We used a between-subjects design since we anticipated carryover effects (Bartels et al., 2015). We expected deliberative donors' moral character to be evaluated less positively compared to empathic donors and "mixed" donors. We anticipated deliberative donors (compared to empathic donors and "mixed" donors) to be judged as less empathic (manipulation check), less guided by moral motives and authentic prosocial motivation, less desirable as social partners, and less trustworthy. For these measures, we expected to fail to find differences between empathic donors and "mixed" donors. We also expected deliberative donors and "mixed" donors to be judged as more reasonable, more competent, and more guided by pragmatic motives (compared to empathic donors). For these measures, we expected to fail to find differences between deliberative donors and "mixed" donors. Thus, we expected donors engaging in both approaches to reap the reputational benefits of each approach without incurring the respective reputational costs.

\section{Method}

Participants. We aimed to collect 300 participants (100 per condition). 302 participants completed our survey (134 Males, 168 Females, $M_{\text {age }}=36.03, S D_{\text {age }}=11.95$, age range $=18-74) .8$ out of the 302 participants $(3 \%)$ failed the attention check. There were 102 participants in the empathy condition, 102 participants in the deliberation condition, and 98 participants in the mixed condition.

Procedure. We employed the scenario used in the previous study (i.e., donating to help a child in Africa), and made a few changes to rule out potential confounds. To ameliorate the possibility that the charity fundraiser is perceived as unreliable, we presented it as a "fundraiser of a registered charity" rather than a "charity fundraiser". In the deliberation condition, we added that the donor "took some time to compare it with information of other charities" to capture the comparison element of cost-effectiveness. In the new "mixed" 
DOES MAXIMIZING GOOD MAKE PEOPLE LOOK BAD?

condition, the donor was moved by the recipient of the donation, but overcame his empathic reaction and took a deliberative approach to donating:

John was deeply moved by Rokia's situation and about how terrible her situation must be for her. After hearing about her tragic story and imagining how his donation could help her John wanted to help Rokia. However, John thought that donating to help Rokia might not be the most cost--effective way to use his money and that maybe he should donate to a charity doing something more cost-effective instead. He asked the charity fundraiser about the relevant statistics of the program, took some time to compare it with information of other charities, and since the data suggested this charity was the most cost--effective John donated to the charity.

For all conditions, the donor ended up donating to help Rokia.

Measures. The main measures we used were the same as the previous study. We measured moral character $(\alpha=0.91)$, character traits (empathy, $\alpha=0.93$; reasonableness, $\alpha=$ 0.92, and competence, $\alpha=0.92$ ), motives (moral, $\alpha=0.84$, and pragmatic, $\alpha=0.80$ ), authentic prosocial motivation $(\alpha=0.85)$, desirability as social partners $(\alpha=0.93)$, and trustworthiness. We checked whether participants were moved by Rokia's situation, and included an open question (“Does anything seem negative about John's way of thinking/feeling?"). For exploratory purposes, we measured perceptions of amount donated (“How much do you think John donated (in dollars)?”; slider: 0-1,000 US dollars), selfishness ("How selfish do you think John is?"; 1 = Not at all, 7 = Extremely), altruism ("How altruistic do you think John is?"; 1 = Not at all, 7 = Extremely), and importance of deciding deliberatively ("How important do you think it is to carefully consider evidence when making a decision?"; 1 = Not at all, 7 = Extremely) and emotionally ("How important do you think it is to follow your emotions and intuitions when making a decision?"; $1=$ Not 
DOES MAXIMIZING GOOD MAKE PEOPLE LOOK BAD?

at all, $7=$ Extremely). We included an attention check, and the same sociodemographics and exit questions as Study 3.

\section{Results}

We examined overall differences in the measures depending on the condition (i.e., omnibus tests), and pairwise comparisons (using the Holm adjustment) to examine specific group differences: “empathy minus deliberation", "mixed minus deliberation”, and "mixed minus empathy". We calculated unstandardized mean differences and computed 95\% confidence intervals around them (only $p$ values were adjusted using the Holm adjustment, confidence intervals were not adjusted). To check whether the scenario triggered empathy, we conducted a one sample $t$-test (one-sided) on empathy felt for Rokia to examine whether it was significantly higher than the scale midpoint (4).

All omnibus tests were significant $(p<.05)$, except trustworthiness $(p=.056)$. Since our interest lies in the group comparisons, we focus on these. As expected, the manipulation check showed that deliberative donors were evaluated as less empathic than empathic donors, $M_{\text {diff }}=1.24,95 \% \mathrm{CI}[0.93,1.56], t(299)=7.76, p<.001$, as well as "mixed" donors, $M_{\text {diff }}=$ $0.88,95 \%$ CI $[0.56,1.20], t(299)=5.43, p<.001$. Contrary to predictions, empathic donors were rated as more empathic than "mixed" donors, $M_{\text {diff }}=-0.37,95 \%$ CI $[-0.68,-0.05], t(299)$ $=-2.26, p=.025$. In addition, participants appeared to be moved by Rokia's situation, since the mean empathy felt for Rokia was above the midpoint, $M=5.51,95 \%$ CI [5.38, Inf], $t(301)=19.46, p<.001$.

As expected, deliberative donors' moral character was evaluated less positively compared to empathic donors, $M_{\text {diff }}=0.58,95 \% \mathrm{CI}[0.33,0.83], t(299)=4.53, p<.001$, and compared to mixed donors, $M_{\text {diff }}=0.39,95 \%$ CI $[0.14,0.65], t(299)=3.05, p=.005$. As predicted, we failed to find differences in moral character between empathic and mixed donors, $M_{\text {diff }}=-0.19,95 \%$ CI [-0.44, 0.07], $t(299)=-1.44, p=.151$ (see Figure 1$)$. 
DOES MAXIMIZING GOOD MAKE PEOPLE LOOK BAD?

Unexpectedly, we failed to find differences in perceived reasonableness and competence between deliberative and empathic donors, reasonableness: $M_{\text {diff }}=-0.26,95 \%$ CI $[-0.57$, 0.06], $t(299)=-1.61, p=.194$, competence: $M_{\text {diff }}=-0.25,95 \%$ CI $[-0.57,0.08], t(299)=-$ $1.49, p=.217$, though, as expected, "mixed" donors were evaluated as more reasonable and competent than empathic donors, reasonableness: $M_{\text {diff }}=0.52,95 \%$ CI $[0.21,0.83], t(299)=$ $3.26, p=.004$, competence: $M_{\text {diff }}=0.51,95 \%$ CI $[0.19,0.84], t(299)=3.09, p=.007$, and we failed to find differences in reasonableness and competence between "mixed" and deliberative donors, reasonableness: $M_{\text {diff }}=0.27,95 \%$ CI $[-0.05,0.58], t(299)=1.67, p=$ .194 , competence: $M_{\text {diff }}=0.27,95 \%$ CI $[-0.06,0.59], t(299)=1.61, p=.217$. As anticipated, deliberative donors were perceived to be less guided by moral motives than empathic donors, $M_{\text {diff }}=0.71,95 \%$ CI $[0.39,1.03], t(299)=4.32, p<.001$, and "mixed" donors, $M_{\text {diff }}=0.64$, $95 \%$ CI $[0.32,0.97], t(299)=3.89, p<.001$. Also as expected, we failed to find differences in moral motives between empathic and "mixed" donors, $M_{\text {diff }}=-0.06,95 \%$ CI $[-0.39,0.26]$, $t(299)=-0.38, p=.701$. In line with expectations, empathic donors were evaluated as less guided by pragmatic motives than deliberative donors, $M_{\text {diff }}=-0.77,95 \%$ CI $[-1.10,-0.43]$, $t(299)=-4.49, p<.001$, and "mixed" donors, $M_{\text {diff }}=1.02,95 \%$ CI $[0.68,1.36], t(299)=5.92$, $p<.001$, plus we failed to find differences between deliberative and "mixed" donors, $M_{\text {diff }}=$ $0.25,95 \%$ CI $[-0.08,0.59], t(299)=1.48, p=.141$. As predicted, deliberative donors were evaluated as less guided by authentic prosocial motivation compared to empathic donors, $M_{\text {diff }}=0.91,95 \%$ CI $[0.62,1.21], t(299)=6.07, p<.001$, and “mixed" donors, $M_{\text {diff }}=0.81$, $95 \%$ CI $[0.51,1.11], t(299)=5.33, p<.001$, plus we failed to find differences between empathic and "mixed" donors, $M_{\text {diff }}=-0.10,95 \%$ CI $[-0.40,0.20], t(299)=-0.68, p=.497$. As predicted, deliberative donors were rated as less desirable as social partners compared to empathic donors, $M_{\text {diff }}=0.82,95 \%$ CI $[0.46,1.18], t(299)=4.48, p<.001$, and "mixed" donors, $M_{\text {diff }}=0.66,95 \%$ CI $[0.29,1.02], t(299)=3.55, p<.001$, plus we failed to find 
DOES MAXIMIZING GOOD MAKE PEOPLE LOOK BAD?

differences between "mixed" and empathic donors, $M_{\text {diff }}=-0.16,95 \%$ CI $[-0.53,0.20], t(299)$ $=-0.88, p=.381$. Contrary to expectations, we failed to find differences in trustworthiness between deliberative and empathic donors, $M_{\text {diff }}=0.08,95 \%$ CI $[-0.21,0.37], t(299)=0.53, p$ $=.597$, and deliberative and "mixed" donors, $M_{\text {diff }}=0.35,95 \%$ CI $[0.05,0.64], t(299)=2.31$, $p=.065$, though, as expected, we failed to find differences between "mixed" and empathic donors, $M_{\text {diff }}=0.27,95 \%$ CI $[-0.03,0.56], t(299)=1.79, p=.150$.

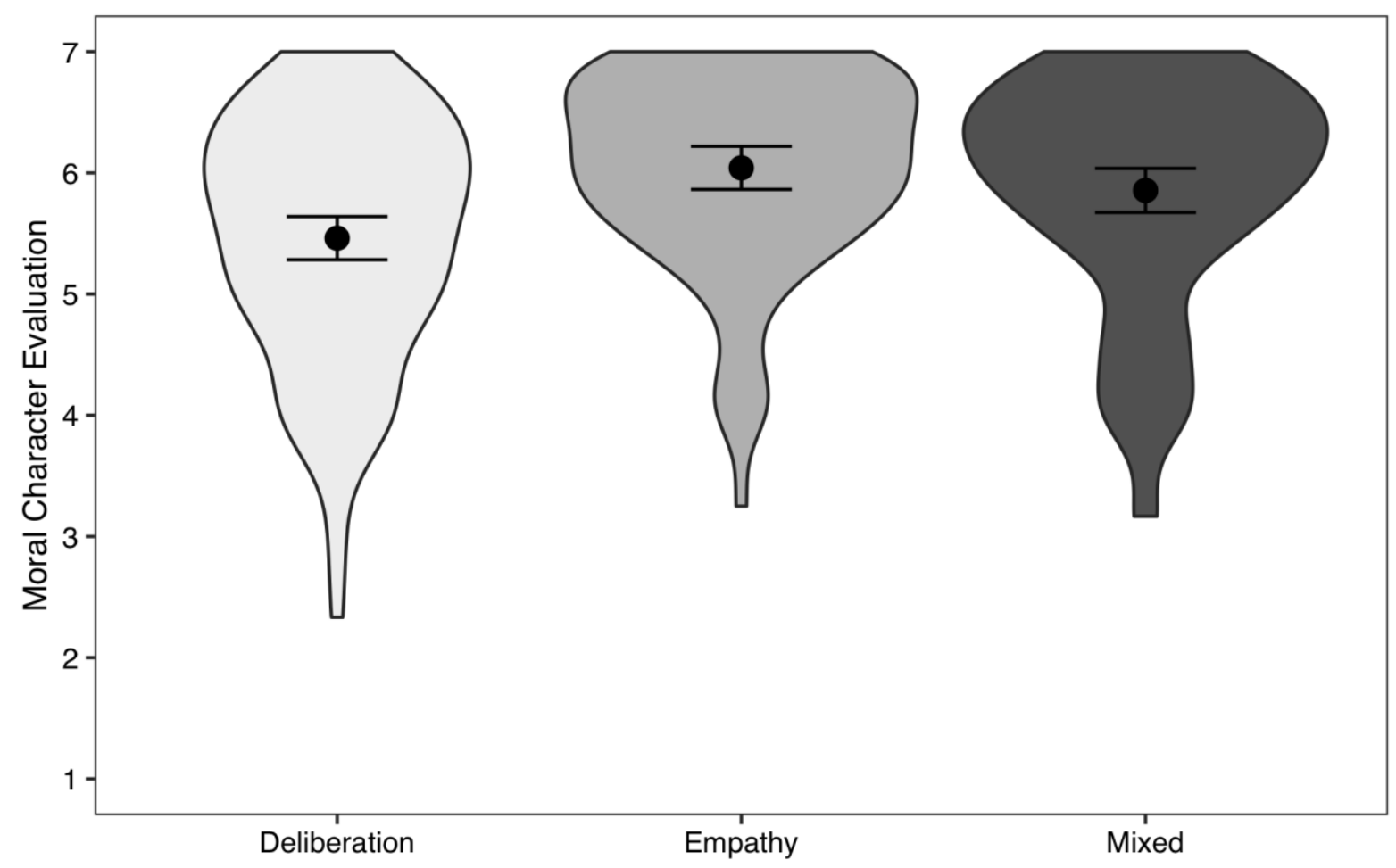

Figure 1. Violin plots of moral character depending on the decision approach in Study 6. Point estimates represent means and error bars represent $95 \%$ confidence intervals. Probability density estimates are overlaid. Moral character was measured on a seven-point scale; higher scores indicate higher perceived moral character.

\section{Discussion}

These results supported most of our predictions regarding empathic and deliberative donors. As predicted, deliberative donors were perceived to have a less positive moral character, were evaluated as less guided by moral motives and authentic prosocial motivation, and were rated as less desirable as social partners, compared to empathic donors. However, we failed to find differences in competence and reasonableness between empathic and 
DOES MAXIMIZING GOOD MAKE PEOPLE LOOK BAD?

deliberative donors; though we found the expected differences in pragmatic motives.

Additionally, expressing empathy, even if followed by deliberation, reduced the reputational costs of deliberating. As expected, mixed donors were evaluated higher in moral character, were perceived to be more guided by moral motives and authentic prosocial motivation, and were rated as more desirable as social partners, compared to deliberative donors. Mixed donors were also evaluated as more competent and reasonable, and were perceived to be more guided by pragmatic motives, compared to empathic donors. Thus, donors could reduce the reputational costs of appearing cold while donating cost-effectively by empathizing before deliberating.

One limitation of Studies 5 and 6 is that, for some hypotheses, we predicted lack of significant differences compared to zero, rather than specifying a smallest effect size of interest and testing for the absence of effects using equivalence tests (Lakens et al., 2018). Therefore, for these results we can only conclude that we failed to find effects, but we cannot provide evidence for the absence of effects.

\section{Study 7}

In this study, we tested one potential concern with the manipulation of deliberation employed in Studies 1-4. In these studies, we manipulated deliberation by indicating that the respondent would donate to the charity that spends its donations most cost-effectively. We assumed that participants would interpret this to mean donating to the charity which does the greatest amount of good for a given amount of money. We also assumed that participants would interpret the motivation of these respondents to be to do the most good with their donation. Yet, participants may not understand what donating to the most cost-effective charity means, or they may make additional, distinct inferences about the motivations of these donors. For instance, participants may infer that respondents donating to the most cost- 
DOES MAXIMIZING GOOD MAKE PEOPLE LOOK BAD?

effective charity are motivated by stinginess or lack of generosity (wanting to do good while spending as little as possible), rather than a motivation to do the most good they can with fixed resources. If this is the case, participants may judge deliberative donors negatively for reasons unrelated to our reputational account (e.g., participants may dislike stingy donors). To evaluate this concern, in this study we test whether our prior results regarding perceptions of deliberative and empathic donors hold when we use a manipulation of deliberation that avoids using the term "cost-effectiveness", and instead explains directly what costeffectiveness means in this context. To do this, we included the deliberation and empathy conditions of Study 1 (deliberation-original and empathy), and added a modified deliberation condition that avoids using the term "cost-effectiveness" (deliberation-modified). Thus, the study had three conditions: deliberation-original, deliberation-modified, and empathy (between-subjects). We expected to find similar results when comparing deliberation-original and empathy, and deliberation-modified and empathy. We had no predictions regarding the comparison of deliberation-original and deliberation-modified.

\section{Method}

Participants. We aimed to recruit 600 participants (200 per condition). 601 participants completed our survey (285 Males, 313 Females, and 3 Other, $M_{\text {age }}=39.80, S D_{\text {age }}$ $=12.28$, age range $=18-73$ ). There were 203 participants in the deliberation-original condition, 199 in the deliberation-modified condition, and 199 in the empathy condition.

Procedure. Our deliberation-original and empathy conditions were identical to the ones in Study 1, and we added a deliberation-modified condition. In the deliberation-original condition, we used the following wording: "I would use evidence to calculate which charity spends its donations most cost effectively, and donate to them". In the deliberation-modified condition, we used the following wording: "I would use evidence to calculate which charity generates the most good for a given amount of money, and donate to them". Hence, the only 
DOES MAXIMIZING GOOD MAKE PEOPLE LOOK BAD?

difference between the deliberation conditions is that the deliberation-modified condition explains cost-effectiveness directly rather than relying on the term "cost-effectiveness".

Measures. We only included the main measures from Study 1: moral character $(\alpha=$ 0.92), character traits (empathy, $\alpha=0.93$; reasonableness, $\alpha=0.91$; competence, $\alpha=0.91$ ), motives (moral, $\alpha=0.77$; pragmatic, $\alpha=0.75$ ), and desirability as social partners $(\alpha=0.91$ ). In addition, we included a single-item measure of moral character: "How morally good of a person is John?" ( 1 = Very morally bad, $4=$ Neither morally good nor bad, $7=$ Very morally good). This measure allows us to examine whether the 12-item moral character results are robust to using a measure that relies on people's folk understanding of moral character, rather than using specific positive or negative traits. Additionally, this measure reduces concerns, which may apply to our previous 12-item measure, about conflating warmth and moral character (Goodwin et al., 2014).

\section{Results}

We fit one-way ANOVAs to examine whether there are differences in each measure depending on the condition, and performed pairwise comparisons (using the Holm adjustment) to examine specific group differences: "empathy minus deliberation-original", “empathy minus deliberation-modified", and "deliberation-modified minus deliberationoriginal". We calculated unstandardized mean differences and computed $95 \%$ confidence intervals around them (only $p$ values were adjusted using the Holm adjustment, confidence intervals were not adjusted).

We did not pre-register omnibus tests, and instead focused on group comparisons, where our interest lies. As expected, the manipulation check showed that deliberative donors were evaluated as less empathic than empathic donors, empathy minus deliberation-original: $M_{\text {diff }}=0.98,95 \%$ CI $[0.75,1.20], t(598)=8.50, p<.001$; empathy minus deliberationmodified: $M_{\text {diff }}=0.79,95 \%$ CI $[0.57,1.02], t(598)=6.87, p<.001$. We failed to find 
DOES MAXIMIZING GOOD MAKE PEOPLE LOOK BAD?

differences in empathy between the deliberation-original and the deliberation-modified conditions, $M_{\text {diff }}=0.18,95 \%$ CI $[-0.04,0.41], t(598)=1.60, p=.111$.

For every measure, we replicate our prior findings (empathy vs. deliberation-original), as well as find similar results using the modified manipulation of deliberation (empathy vs. deliberation-modified). As predicted, deliberative respondents were rated lower in the 12item measure of moral character, empathy minus deliberation-original: $M_{\text {diff }}=0.57,95 \% \mathrm{CI}$ $[0.41,0.73], t(598)=7.06, p<.001 ;$ empathy minus deliberation-modified: $M_{\text {diff }}=0.31,95 \%$ CI $[0.15,0.47], t(598)=3.81, p<.001$, as well as on the single-item measure of moral character, empathy minus deliberation-original: $M_{\text {diff }}=0.43,95 \% \mathrm{CI}[0.24,0.62], t(598)=$ 4.50, $p$ <.001; empathy minus deliberation-modified: $M_{\text {diff }}=0.20,95 \%$ CI $[0.01,0.39]$, $t(598)=2.09, p=.037$. As expected, deliberative respondents were rated higher in reasonableness, empathy minus deliberation-original: $M_{\text {diff }}=-0.38,95 \%$ CI $[-0.56,-0.20]$, $t(598)=-4.12, p<.001 ;$ empathy minus deliberation-modified: $M_{\text {diff }}=-0.43,95 \%$ CI [-0.61, $0.25], t(598)=-4.67, p<.001$, and competence, empathy minus deliberation-original: $M_{d i f f}=$ $-0.32,95 \%$ CI $[-0.52,-0.11], t(598)=-3.05, p=.005$; empathy minus deliberation-modified: $M_{\text {diff }}=-0.37,95 \%$ CI $[-0.57,-0.16], t(598)=-3.52, p=.001$. As predicted, deliberative respondents were evaluated as less guided by moral motives, empathy minus deliberationoriginal: $M_{\text {diff }}=0.57,95 \% \mathrm{CI}[0.37,0.77], t(598)=5.55, p<.001$; empathy minus deliberation-modified: $M_{d i f f}=0.24,95 \%$ CI $[0.04,0.45], t(598)=2.36, p=.019$, more guided by pragmatic motives, empathy minus deliberation-original: $M_{\text {diff }}=-0.36,95 \% \mathrm{CI}[-0.56,-$ $0.17], t(598)=-3.62, p<.001$; empathy minus deliberation-modified: $M_{\text {diff }}=-0.48,95 \%$ CI [$0.68,-0.28], t(598)=-4.71, p<.001$, and as less desirable as social partners, empathy minus deliberation-original: $M_{\text {diff }}=0.62,95 \%$ CI $[0.39,0.85], t(598)=5.30, p<.001$; empathy minus deliberation-modified: $M_{\text {diff }}=0.51,95 \%$ CI $[0.28,0.74], t(598)=4.34, p<.001$. 
DOES MAXIMIZING GOOD MAKE PEOPLE LOOK BAD?

Although we did not have any predictions, we found some differences between the deliberation-original and the deliberation-modified conditions. In particular, for moral measures, the deliberation-modified condition fell between the deliberation-original and empathy conditions: we found that the deliberation-original respondents were rated lower in moral character, 12-item measure: $M_{\text {diff }}=0.26,95 \%$ CI $[0.10,0.42], t(598)=3.23, p=.001$; single-item measure: $M_{\text {diff }}=0.23,95 \%$ CI $[0.04,0.42], t(598)=2.40, p=.033$, and were perceived as less guided by moral motives, $M_{\text {diff }}=0.33,95 \% \mathrm{CI}[0.12,0.53], t(598)=3.18, p$ $=.003$. However, we failed to find any differences in reasonableness, $M_{\text {diff }}=0.05,95 \%$ CI [$0.13,0.23], t(598)=0.57, p=.57$, competence, $M_{\text {diff }}=0.05,95 \%$ CI $[-0.15,0.26], t(598)=$ $0.49, p=.63$, pragmatic motives, $M_{\text {diff }}=0.11,95 \%$ CI $[-0.09,0.31], t(598)=1.12, p=.26$, and desirability as social partners, $M_{\text {diff }}=0.11,95 \%$ CI $[-0.12,0.34], t(598)=0.94, p=.35$.

\section{Discussion}

These results suggest that prior findings regarding perceptions of deliberative and empathic donors hold when using manipulation of deliberation that avoids the term "costeffectiveness". In particular, we replicated every prior finding using our original manipulations of deliberation and empathy, and found similar results using a modified manipulation of deliberation. Additionally, our modified deliberation manipulation was perceived to be roughly similar to our original deliberation manipulation, with some differences in moral dimensions. In particular, the original deliberation manipulation was rated lower on moral measures, perhaps because the term cost-effectiveness may have a negative connotation in this context and therefore using the term may communicate negative characteristics about a person. Although this slightly alters the magnitude of our original effects on moral measures, our conclusions remain unchanged.

In prior studies, we have examined people's judgments of empathic or deliberative donors. This is important for our reputational account, since if people do not judge others 
DOES MAXIMIZING GOOD MAKE PEOPLE LOOK BAD?

depending on their decision process it is unclear whether others have a reputational incentive to avoid deliberating. However, it is also important to examine if people anticipate these negative reputational costs, since people could judge others' differently and yet not anticipate the negative reputational costs in their own behavior. This is what we examine in our next study.

\section{Study 8}

In this study, we examine if people anticipate being evaluated more negatively if they take a deliberative rather than an empathic approach to donating to charity. To test this, we ask participants to anticipate how others' would evaluate them if they donate based on a deliberative or empathic approach. Thus, the study had two conditions: deliberation and empathy (within-subjects). We also use two different scenarios that are based on our prior paradigms (between-subjects). We focus on two key dependent variables: moral character and desirability as social partners. For each of the scenarios, we expect participants to anticipate being evaluated as having a worse moral character and be less desirable as social partners if they take a deliberative rather than an empathic approach to donating to charity.

\section{Method}

Participants. We aimed to recruit 400 participants (200 per scenario). 400 participants completed our survey (226 Males, 173 Females, and 1 Other, $M_{\text {age }}=40.23, S D_{\text {age }}$ $=12.38$, age range $=18-83)$. There were 200 participants in each scenario.

Procedure. We adapted each of the two paradigms that we used in our prior studies: the survey response scenario used in Studies 1-4 and 7, and the child living in extreme poverty scenario used in Studies 5-6. For the survey response scenario, we asked participants to imagine that they were intending to donate to a charity, and they were deciding what charity to donate to. For the child living in extreme poverty scenario, we asked participants to 
DOES MAXIMIZING GOOD MAKE PEOPLE LOOK BAD?

imagine that they were approached by a charity fundraiser and asked whether they would be interested in donating to help a child living in extreme poverty. We then asked participants which approach they would take (empathy vs. deliberation), and we asked them how they expect to be evaluated depending on each approach (empathy vs. deliberation).

Measures. To ensure the robustness of our results to different question formats, we measured anticipated reputational costs in two ways: (1) Ordinal scale format: Participants rated how other people would evaluate their moral character or desirability as a social partner if they donated based on a deliberative or empathic approach (moral character: $1=$ A morally bad person, 4 = Neither morally good nor bad person, 7 = A morally good person; desirability as a social partner: $1=$ An undesirable social partner, 7 = A desirable social partner). For each scenario (survey response scenario and child living in extreme poverty scenario), we asked participants to rate how other people would evaluate them if they took a deliberative or empathic approach, for both moral character and desirability as social partners, separately (4 questions per scenario). (2) Categorical format: Participants selected which approach to donating would lead other people to rate them as a morally better person or a more desirable social partner (2-choices, empathy vs. deliberation). We asked this question separately for moral character and desirability as social partners (2 questions per scenario). As an exploratory measure, in each scenario we ask participants which donation approach they would take (empathy vs. deliberation).

\section{Results}

We performed the following analyses separately for each scenario. For the ordinal scale format questions, we ran paired $t$-tests (using repeated measures ANOVA) and calculated unstandardized mean differences (empathy minus deliberation) and 95\% confidence intervals around them. We ran this analysis for moral character and desirability as social partners separately. For the categorical format questions, we ran one-sample proportion 
DOES MAXIMIZING GOOD MAKE PEOPLE LOOK BAD?

tests (with continuity correction) and calculated the proportion who selected deliberation (over empathy) and estimated $95 \%$ confidence intervals around the estimate. We ran this analysis for moral character and desirability as a social partner separately. For the question of which approach they would take, we also ran one-sample proportion tests.

Survey response scenario. Participants anticipated being evaluated as having a less positive moral character if they took a deliberative rather than an empathic approach: ordinal scale question: $M_{\text {diff }}=0.58,95 \%$ CI $[0.39,0.77], t(199)=5.95, p<.001$; categorical question: proportion $=0.17$ (deliberation), $95 \%$ CI $[0.12,0.23], X^{2}(1)=85.81, p<.001$. Participants also anticipated being evaluated as less desirable social partners if they took a deliberative rather than an empathic approach: ordinal scale question: $M_{\text {diff }}=0.70,95 \%$ CI $[0.48,0.92]$, $t(199)=6.18, p<.001$; categorical question: proportion $=0.27$ (deliberation), 95\% CI [0.21, 0.33], $X^{2}(1)=43.25, p<.001$. We failed to find evidence that people favor one approach over the other, proportion $=0.54$ (deliberation), $95 \% \mathrm{CI}[0.46,0.61], X^{2}(1)=0.85, p=.36$.

Child living in extreme poverty scenario. Participants anticipated being evaluated as having a less positive moral character if they took a deliberative rather than an empathic approach: ordinal scale question: $M_{\text {diff }}=1.59,95 \%$ CI $[1.36,1.83], t(199)=13.64, p<.001$; categorical question: proportion $=0.11$ (deliberation), 95\% CI $[0.07,0.16], X^{2}(1)=123.25, p$ $<.001$. Participants also anticipated being evaluated as less desirable social partners if they took a deliberative rather than an empathic approach: ordinal scale question: $M_{d i f f}=1.53$, $95 \%$ CI $[1.26,1.80], t(199)=11.15, p<.001$; categorical question: proportion $=0.18$ (deliberation), $95 \%$ CI $[0.13,0.24], X^{2}(1)=83.21, p<.001$. Again, we failed to find evidence that people favor one approach over the other, proportion $=0.45$ (deliberation), $95 \%$ CI $[0.38,0.52], X^{2}(1)=2.21, p=.138$.

\section{Discussion}


DOES MAXIMIZING GOOD MAKE PEOPLE LOOK BAD?

We found that people anticipate being evaluated more negatively if they take a deliberative rather than an empathic approach to donating to charity. We found these results for moral character and desirability as social partners (using both ordinal scale and categorical questions). We also found these results across two different scenarios. We appear to find stronger results for the child living in extreme poverty scenario (compared to the survey response scenario), perhaps because the former scenario involves a more concrete social situation that increases the anticipated reputational costs. However, when asked which approach they would take, we failed to find evidence that people select one approach over the other, perhaps because they experience a conflict between donating to a more impactful but less emotional charity and a less impactful but more emotional charity. Alternatively, this could be due to a demand effect, with people inferring that the deliberative approach is the normative response. We suspect that in concrete social situations with social stakes in which the possibility of deliberating about impact is not made explicitly salient, most people would not donate deliberatively. In sum, the results of the study suggest that people are aware of the negative reputational costs associated with donating based on a deliberative approach.

We now turn to the intriguing question of whether people who favor deliberative approaches, such as effective altruists, are also aware of these negative reputational costs. In our next study, we recruit a sample of effective altruists and ask them if they anticipate negative reputational costs from donating deliberatively.

\section{Study 9}

In this study, we examine how effective altruists expect others' to evaluate their moral character depending on their donation approach. We focus on effective altruists since they have a commitment to helping others effectively, and they might therefore have first hand experience with the negative reputational costs associated with donating deliberatively. 
DOES MAXIMIZING GOOD MAKE PEOPLE LOOK BAD?

Effective altruists might support effective altruist ideas despite the negative reputational costs either because they do not care too much about the reputational costs or care about other things more (e.g., doing what is right over what is socially desirable), or because they are embedded in social circles that favor different norms towards effective giving (in which donating deliberatively is evaluated more positively than donating empathically). For this last reason, we ask effective altruists about their anticipated reputational consequences separately for non-effective altruists and effective altruists (i.e., how would someone who is an effective altruist vs. a non-effective altruist judge them). Thus, the study has a 2 (decision approach: deliberation vs. empathy) x 2 (evaluators: non-effective altruists vs. effective altruists) fully within-subjects design. Although we suspect that effective altruists are aware of the negative reputational costs, we recognize that another possibility (which we consider less plausible) is that effective altruists are unaware of these negative reputational costs (perhaps because they incorrectly assume that other people share their beliefs and values). For this reason, we have no directional predictions (we only preregister the analysis).

\section{Method}

Participants. We aimed to recruit as many effective altruists as possible during a certain timeframe. With the help of an effective altruist organization, we sent the survey to a sample of 877 effective altruists who previously indicated interest in answering surveys. We reached out to them on April 30, 2021, and we included participants who answered the survey until June 11, 2021 (this timeframe was pre-registered). 364 participants completed our survey (84 women, 254 men, 22 non-binary or third gender, 3 who prefered not to say, and 1 unreported, $M_{\text {age }}=30.20, S D_{\text {age }}=8.73$, age range $\left.=18-72\right) .95 .6 \%$ of participants confirmed that they considered themselves to be involved in effective altruism or the effective altruism community to any degree. 
DOES MAXIMIZING GOOD MAKE PEOPLE LOOK BAD?

Procedure. The procedure was similar to the one employed in Study 8. Since we were able to include only a subset of questions in the study (our study was part of a larger survey administered to effective altruists), we decided to focus on the survey response scenario (our main paradigm) and on moral character evaluations (our main dependent variable). Specifically, we asked participants to imagine that they were intending to donate to a charity and they were deciding what charity to donate to. We then asked participants which approach they would take (empathy vs. deliberation), and we asked them about their anticipated reputational evaluations (moral character) depending on each approach (empathy vs. deliberation) and each evaluator (non-effective altruists vs. effective altruists).

Measures. Participants rated how people who are involved (or not involved) in effective altruism would evaluate their moral character if they donated based on a deliberative or empathic approach $(1=$ A morally bad person, $4=$ Neither morally good nor bad person, 7 = A morally good person). We asked this question separately for non-effective altruists and effective altruists, and deliberation and empathy (4 questions in total). We also asked participants which approach they would take (deliberation vs. empathy).

\section{Results}

For the main dependent variable (anticipated reputational concerns), we fitted a twoway repeated measures ANOVA (decision approach x evaluators; full model), and estimated the interaction and simple effects (the effect of decision approach, "empathy minus deliberation", separately for non-effective altruists and for effective altruists). We calculated unstandardized mean differences and 95\% confidence intervals around them. For the question of which approach they would take, we ran a one-sample proportion test (with continuity correction) and calculated the proportion who selected deliberation (over empathy) and estimated $95 \%$ confidence intervals around the estimate. 
DOES MAXIMIZING GOOD MAKE PEOPLE LOOK BAD?

For our main dependent measure, we found a significant and large crossover interaction effect, $M_{\text {diff }}=-2.97,95 \%$ CI [-3.18, -2.77], $t(362)=-28.56, p<.001$, with participants anticipating being evaluated as having a less positive moral character if they took a deliberative approach when evaluated by non-effective altruists, $M_{\text {diff }}=1.28,95 \%$ CI [1.15, 1.40], $t(362)=19.50, p<.001$, but anticipating being evaluated as having a more positive moral character if they took a deliberative approach when evaluated by effective altruists, $M_{\text {diff }}=-1.70,95 \%$ CI $[-1.85,-1.54], t(362)=-21.93, p<.001$. Unsurprisingly, we found that participants strongly favor a deliberative over an empathic approach, proportion $=0.96$ (deliberation), $95 \%$ CI $[0.93,0.98], X^{2}(1)=306.32, p<.001$.

\section{Discussion}

These results suggest that effective altruists' anticipated reputational evaluations depend on the audience evaluating them. Effective altruists correctly infer that non-effective altruists will evaluate them less positively for favoring a deliberative over an empathic approach to donating, but effective altruists will evaluate them more positively for favoring a deliberative over an empathic approach to donating. Prior research has found that although people recognize that overseas charities are often more effective, they think that donors should donate to a local charity that donors have an emotional connection with (Baron \& Szymanska, 2011; Berman et al., 2018). Our results suggest that effective altruists have modified norms around effective giving, insofar as effective altruists think that other effective altruists would praise them for donating to effective charities over donating to causes that they have an emotional connection with. Furthermore, in contrast to the findings of our previous study in which people did not clearly favor a deliberative or empathic approach, effective altruists overwhelmingly favor a deliberative approach. Future research could investigate what psychological features differentiate effective altruists from other people, 
DOES MAXIMIZING GOOD MAKE PEOPLE LOOK BAD?

facilitating more impactful helping behaviors and more beneficial norms around effective giving.

\section{General Discussion}

Across nine studies, we report evidence for two findings. First, in Studies 1-7 we find that donors who deliberate about the cost-effectiveness of charities rather than empathize with the recipients of the donation suffer negative reputational consequences. In particular, "deliberators" are perceived to have a less positive moral character and are rated as less desirable as social partners. To make it easier to evaluate these results across studies, we plotted the unstandardized mean differences in moral character and desirability as social partners depending on the decision approach (see Figures 2 and 3). ${ }^{11}$ Yet "deliberators" also gained some reputational benefits, such as being perceived as more reasonable and competent. These results were found across different experimental designs (between-subjects, within-subjects), moderating factors (targets of different genders, donations of different stakes), and paradigms (evaluating a survey respondent, evaluating a person donating to charity). Second, in Studies 8-9 we find that people anticipate the negative reputational consequences of deliberating about the cost-effectiveness of charities. Specifically, people correctly anticipate that deliberating would make them appear to have worse moral character and would make them less desirable as social partners. We find this result across different scenarios (evaluating a survey respondent, evaluating a person donating to charity) and different question formats (ordinal scale format, categorical format). We also replicated this finding among effective altruists when we asked them how other non-effective altruists would evaluate them. Yet we observed the opposite result when we ask effective altruists

\footnotetext{
${ }^{11}$ We do not perform internal meta-analyses since we did not set a rule to determine which studies should be included in these analyses prior to their execution, and unless this assumption is met the validity of internal meta-analyses cannot be ensured (Vosgerau, Simonsohn, Nelson, \& Simmons, 2019).
} 
DOES MAXIMIZING GOOD MAKE PEOPLE LOOK BAD?

how other effective altruists would evaluate them, with effective altruists expecting other

effective altruists to evaluate them as having better moral character if they donate based on a deliberative approach.

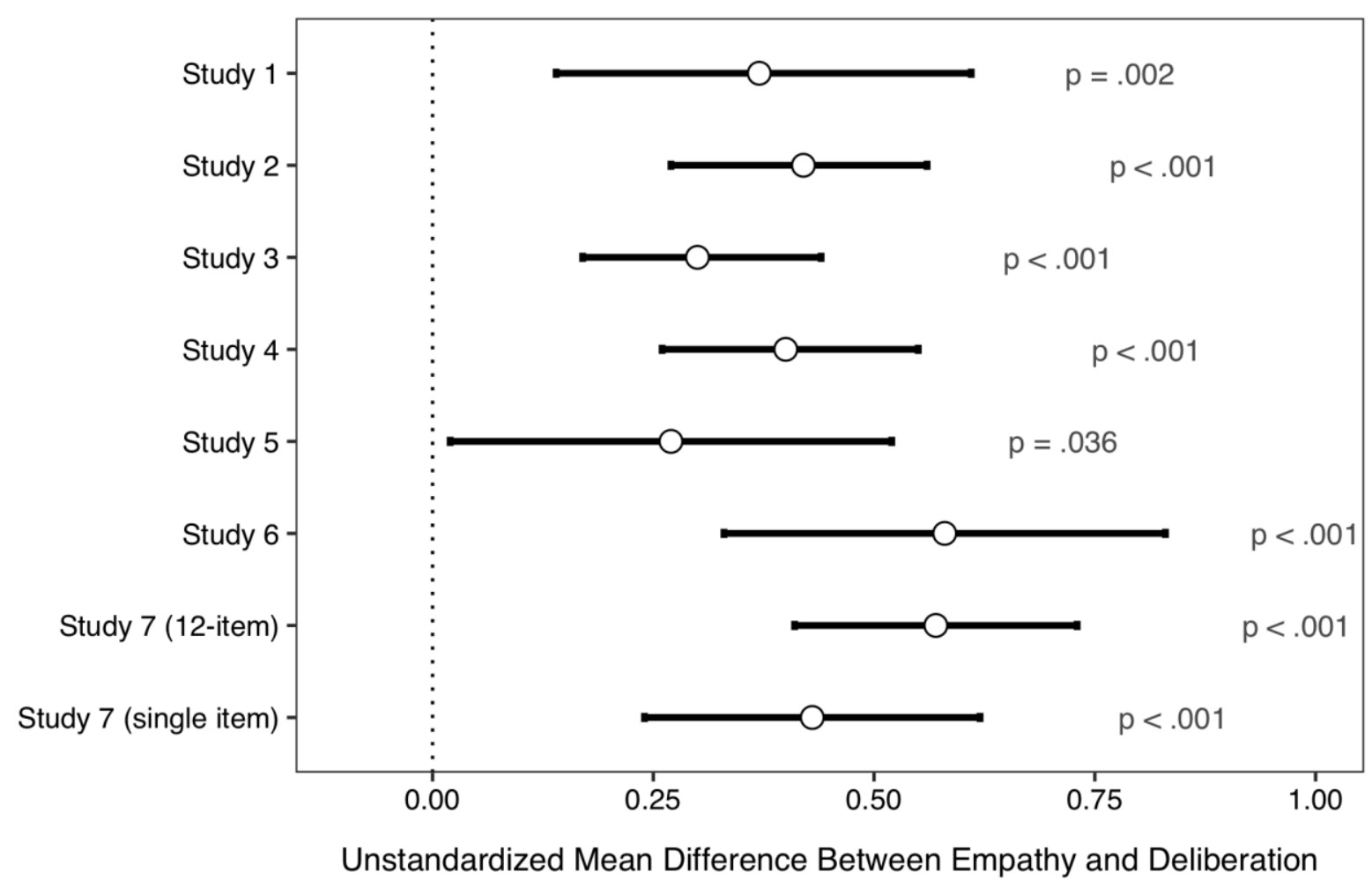

Figure 2. Unstandardized mean differences in moral character evaluation between empathy and deliberation in each study. Moral character was measured on a seven-point scale. Higher scores indicate greater perceived moral character, and positive unstandardized mean differences indicate that the empathy condition was rated higher than the deliberation condition. Error bars represent $95 \%$ confidence intervals. $p$ values are shown on the right. 
DOES MAXIMIZING GOOD MAKE PEOPLE LOOK BAD?

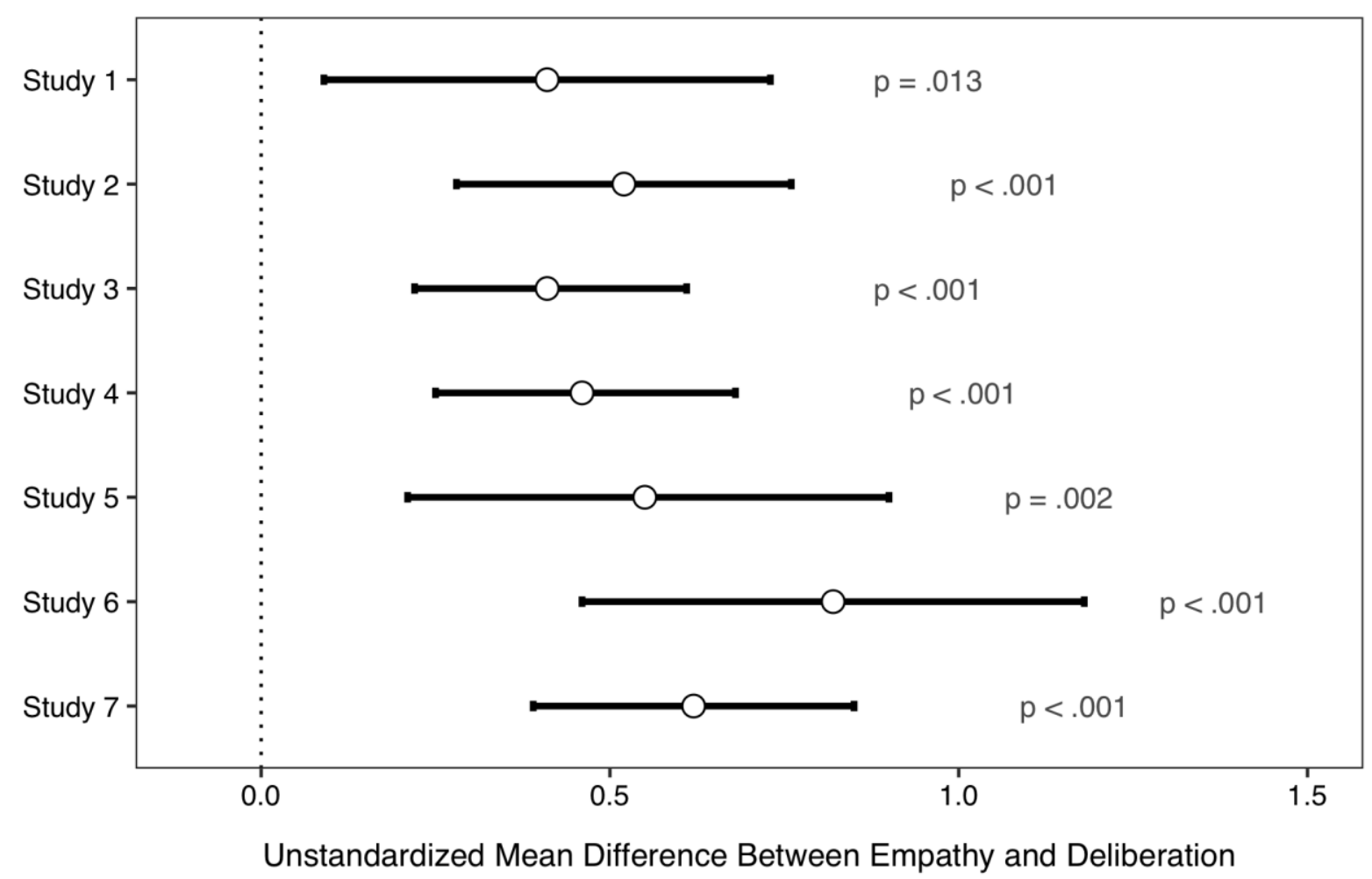

Figure 3. Unstandardized mean differences in desirability as social partners between empathy and deliberation in each study. Desirability as social partners was measured on a seven-point scale. Higher scores indicate higher desirability as social partners, and positive unstandardized mean differences indicate that the empathy condition was rated higher than the deliberation condition. Error bars represent $95 \%$ confidence intervals. $p$ values are shown on the right.

Although people indicate caring about the cost-effectiveness of their donations, they often donate ineffectively. Most existing accounts argue that ineffective giving is explained by a lack of adequate information or preferences about other things over cost-effectiveness. However, few existing accounts have yet considered the evolutionary adaptive function of a psychology that favors ineffective giving. Here, we argue that ineffective giving may play an adaptive function by allowing people to gain a better reputation (e.g., more positive moral character, more desirable social partner). Although we have not directly shown that people avoid deliberating and instead empathize to maintain their reputation, we have provided evidence that is consistent with this possibility. Our results show that people are aware of the negative reputational implications of favoring effective giving. Namely, people anticipate being evaluated more negatively if they donate deliberatively rather than empathically. Our 
DOES MAXIMIZING GOOD MAKE PEOPLE LOOK BAD?

results also demonstrate that people evaluate "deliberators" as less moral and less desirable social partners than "empathizers". This result is important for our reputational account, since for people to effectively modify their behavior to promote their reputation, there needs to be an audience that is sensitive to their signal. We have shown that donors who modify their behavior and signal empathy rather than deliberation will be evaluated more positively.

Although we have argued that ineffective giving serves a reputation management function, we are agnostic as to whether this results from a genuine tendency to empathize or from strategic efforts to appear empathic. However, the evolutionary origins of morality provide some clues. One possibility is that natural selection could have favored a tendency to genuinely empathize because it allowed people to gain a reputation for being good social partners, insofar as empathy promotes cooperative non-strategic behavior (Frank, 1988). Consistent with this possibility, research has found a link between empathy and prosocial behavior (Eisenberg \& Miller, 1987; Levine et al., 2018). Another reason why evolution might favor a tendency to genuinely experience empathy is that faking emotions is not a reliable strategy for managing one's reputation because it is difficult as well as costly, in that it requires significant effort and carries the risk of being perceived as insincere and dishonest (Sperber \& Baumard, 2012). If people donate to less effective charities because they are moved by the recipients of the donation, this may reflect the non-strategic nature of empathy rather than strategic calculation. Another, not mutually exclusive, possibility is that natural selection favored a strategic tendency to regulate one's emotional displays in response to other people (Sperber \& Baumard, 2012), e.g., by attending to situational cues that one is being watched or behaving differently when other people are watching. Consistent with this, there is a large body of evidence suggesting that people behave more prosocially when their behavior is public (e.g., Barclay, 2004; Jordan et al., 2016; Rege \& Telle, 2004). Importantly, this strategic component need not manifest as a deliberate control of one's behavior (even 
DOES MAXIMIZING GOOD MAKE PEOPLE LOOK BAD?

though it can), since people can simply behave strategically by reflexively paying more attention to their behavior when there are cues that others may be watching. In fact, we believe that evolution probably favored both genuine and strategic components since the strategic component gives people extra motivation and flexibility to behave morally in situations in which other people are evaluating their behavior (Sperber \& Baumard, 2012). For this reason, even though people may be donating to charity out of a genuine concern for the recipients of the donation, they may also intentionally or unintentionally adapt their behavior to appear empathic when others are watching.

Our findings suggest that any approach to donations that involves deliberating, including the stance favored by effective altruists and the approach some utilitarians may take, may be hard to popularize, since people may suffer reputational costs from exclusively focusing on maximizing the amount of good done instead of acting based on moral traits that others perceive to be important, including empathy. Effective altruist approaches emphasize the use of evidence and reason to determine the most effective charities to donate to, arguing that by doing so we can potentially help many more people in need (MacAskill, 2015). Despite effective altruism's explicit altruistic goal of helping people as much as possible, effective altruism has been criticized for being cold and hyper-rationalistic (Berger \& Penna, 2013; Earle \& Read, 2016). Our results may partly explain why such approaches are often unappealing and, in turn, why people intentionally or unintentionally often fail to prioritize cost-effectiveness when deciding where to donate. For donors, donation decisions may involve a tension between what is good for them personally and what is good for the recipients of the donation. Although deliberating is personally costly (both in effort and reputational costs), it provides a larger benefit to the recipients of the donation. In contrast, empathizing is personally appealing (both because it "feels right" and because it boosts one's reputation) but provides less of a benefit to the recipients of the donation. Empathizing could 
DOES MAXIMIZING GOOD MAKE PEOPLE LOOK BAD?

therefore enhance or maintain the reputation of donors at the expense of a more efficient allocation of resources (if not accompanied by deliberation). ${ }^{12}$ However, our results also suggest that donors may be able to make decisions that maximize the amount of good done while signaling the right kinds of moral traits by displaying empathy before deliberating, thus emphasizing "both the heart and the head" (Singer, 2013). Nevertheless, encouraging donors to signal empathy before donating deliberatively may potentially backfire since donors could view it as manipulative to 'fake' emotions to manage their own reputation. It is a separate question whether donors would be able to convincingly signal empathy while donating deliberatively. A simpler route could be for effective charities to create opportunities for donors to signal emotion with their donations. Yet these remain open questions that would be valuable to test in naturalistic contexts.

In addition to the previously mentioned limitations (in the study discussions), the present findings have other limitations. Perhaps the central limitation is that our results only provide indirect evidence that people's reluctance to donate deliberatively is explained by reputational concerns. Our findings suggest that people derogate "deliberators" and people anticipate the reputational concerns of deliberating, but we do not demonstrate that people intentionally or unintentionally change their approach to manage their reputation. Whether or not they do is an important question for future research. Another limitation is that our results only provide evidence of relative differences in evaluation between people who deliberate or empathize (e.g., people who deliberate are evaluated less positively in moral character than people who empathize). Our findings do not suggest that people who deliberate are evaluated negatively whereas people who empathize are evaluated positively (Reyna, 2017). In fact, "deliberators" were evaluated positively in absolute terms (i.e., their scores are on the upper

\footnotetext{
${ }^{12}$ We are not suggesting that effective altruists are necessarily taking a hit to their reputation in order to do more good. Another possibility is that effective altruists have organized in communities or social groups in which appearing to be competent and reasonable is more important, and thus their behavior is also explained by reputational incentives.
} 
DOES MAXIMIZING GOOD MAKE PEOPLE LOOK BAD?

part of the scale), and people who deliberate were evaluated more positively on some measures. This is reinforced by the fact that non-donors were evaluated much more negatively than people who donated, regardless of their approach.

It is also worth considering the generality of our conclusions (Simons et al., 2017). Since we mainly relied on online Amazon Mechanical Turk samples from the United States, we expect our results to generalize to other MTurk participants or national samples from the United States (Coppock, 2018). Because our samples belong to a WEIRD (Western, Educated, Industrialized, Rich, and Democratic) society, it is unclear whether our findings extend to non-WEIRD populations (Henrich, Heine, et al., 2010).

Our findings include a sample of effective altruists, which extends our paradigm and replicates some of our core results among a distinct and theoretically relevant subculture. However, members of the effective altruist community are still predominantly from WEIRD societies, and if anything represent a more narrow population in terms of their demographic characteristics. As such, we have no direct data about the degree to which our findings would generalize outside members of populations typically studied in social psychology. For this reason, we remain agnostic about the degree to which our findings generalize to non-WEIRD populations. This is because there are plausible grounds for predicting that our findings would broadly generalize, and similarly plausible grounds for suspecting that they would not.

On the one hand, a tendency to judge more favorably people who exhibit empathy over those who exhibit deliberation in prosocial contexts could tap into basic psychological processes that manifest across many different cultures. For instance, our central findings could be seen as an instance of a pancultural concern for reputation management and signaling prosocial personality traits such as empathy that would be seen as desirable in many cultures. 
DOES MAXIMIZING GOOD MAKE PEOPLE LOOK BAD?

On the other hand, WEIRD populations tend to be psychological outliers when results of WEIRD populations are pitted against findings of non-WEIRD populations (Henrich, Heine, et al., 2010). Notably, some of the most prominent differences between WEIRD and non-WEIRD societies concern matters of cooperation and resource allocation. For instance, research employing the Ultimatum Game and Dictator Game among numerous small-scale societies that are culturally distinct from both WEIRD populations and one another reveal remarkable variation in proportion of money offered to others (Henrich, Ensminger, et al., 2010; Henrich et al., 2005, 2006; Henrich, Heine, et al., 2010). Participants from the United States make the highest mean offer of all populations sampled in the Dictator Game, and the second highest for the Ultimatum Game. As Henrich and colleagues conclude (2010), these findings show "that people from industrialized societies consistently occupy the extreme end of the human distribution” (p. 65). Since Ultimatum Game and the Dictator Game are used as behavioral indicators of attitudes about punishment and fairness in prosocial contexts involving distribution of wealth, the fact that US participants are the least representative of any tested population provides at least some reason to suspect that reputational concerns associated with charitable giving addressed here would likewise fail to generalize to culturally distinct populations. In short, existing evidence suggests that WEIRD populations may differ in ways potentially relevant to reputational concerns in charitable giving. Given the conflicting reasons to expect both cross-cultural similarity and cross-cultural differences in how people engage in and perceive others who take an empathic or deliberative approach to giving, the generalizability of our findings to culturally diverse populations remains an open empirical question that awaits future research.

In addition, the results may not generalize to populations less sensitive to social reputational concerns, such as people with autism (Izuma et al., 2011), or to populations trained to think about social decisions through the lens of cost-effectiveness, such as 
DOES MAXIMIZING GOOD MAKE PEOPLE LOOK BAD?

economists (Frank et al., 1993). Finally, although we used more than one set of stimuli and tested multiple moderating factors, our results are still constrained by the limited set of stimuli employed (Yarkoni, 2020). We have no reason to believe that the results depend on other characteristics of the participants, materials, or context (Simons et al., 2017).

\section{Conclusion}

We propose that people donate ineffectively, in part, to avoid the reputational costs of deliberating about the cost-effectiveness of charities. We found two results that are consistent with this claim. First, we find that people who deliberate rather than empathize when deciding where to donate are perceived as less moral and are less preferred as social partners. We found this result across different experimental designs (between-subjects, withinsubjects), moderating factors (targets of different genders, donations of different stakes), and paradigms (evaluating a survey respondent, evaluating a person donating to charity), and we ruled out an alternative explanation to this finding (that the result is explained by a misunderstanding of what donating to the most cost-effective charity means). Second, we find that people anticipate the negative reputational costs of deliberating. Namely, people are aware that deliberating about the cost-effectiveness of charities leads others to evaluate them as less moral and less desirable social partners. Taken together, our results are consistent with the possibility that there are disincentives for selecting charities based on deliberation about the cost-effectiveness of charities, since people are not socially rewarded for prioritizing charitable impact but are rewarded for possessing the moral traits that others perceive to be important, hence explaining why people donate ineffectively. 
DOES MAXIMIZING GOOD MAKE PEOPLE LOOK BAD?

\section{References}

Barasch, A., Levine, E. E., Berman, J. Z., \& Small, D. A. (2014). Selfish or selfless? On the signal value of emotion in altruistic behavior. Journal of Personality and Social Psychology, 107(3), $393-413$.

Barclay, P. (2004). Trustworthiness and competitive altruism can also solve the "tragedy of the commons." Evolution and Human Behavior: Official Journal of the Human Behavior and Evolution Society, 25(4), 209-220.

Barclay, P. (2015). Reputation. In D. M. Buss (Ed.), The Handbook of Evolutionary Psychology (Vol. 10, pp. 1-19). John Wiley \& Sons, Inc.

Baron, J., \& Szymanska, E. (2011). Heuristics and biases in charity. In D. M. Oppenheimer \& C. Y. Olivola (Eds.), The science of giving: Experimental approaches to the study of charity. Psychology Press.

Bartels, D. M., Bauman, C. W., Cushman, F. A., Pizarro, D. A., \& McGraw, A. P. (2015). Moral Judgment and Decision Making. In G. Keren \& G. Wu (Eds.), The Wiley Blackwell Handbook of Judgment and Decision Making (Vol. 63, pp. 478-515). John Wiley \& Sons, Ltd.

Batson, C. D. (2017). The empathy altruism hypothesis what and so what? The Oxford Handbook of Compassion Science, 27-40.

Berger, K., \& Penna, R. M. (2013, November 25). The Elitist Philanthropy of So-Called Effective Altruism. Stanford Social Innovation Review. https://ssir.org/articles/entry/the_elitist_philanthropy_of_so_called_effective_altruism

Berman, J. Z., Barasch, A., Levine, E. E., \& Small, D. A. (2018). Impediments to Effective Altruism: The Role of Subjective Preferences in Charitable Giving. Psychological Science, 29(5), 834-844.

Bloom, P. (2017). Empathy and Its Discontents. Trends in Cognitive Sciences, 21(1), 24-31.

Buhrmester, M., Kwang, T., \& Gosling, S. D. (2011). Amazon's Mechanical Turk: A New Source of Inexpensive, Yet High-Quality, Data? Perspectives on Psychological Science, 6(1), 3-5.

Burum, B., Nowak, M. A., \& Hoffman, M. (2020). An evolutionary explanation for ineffective altruism. Nature Human Behaviour, 4(12), 1245-1257. 
DOES MAXIMIZING GOOD MAKE PEOPLE LOOK BAD?

Caviola, L., Schubert, S., \& Greene, J. D. (2021). The Psychology of (In)Effective Altruism. Trends in Cognitive Sciences. https://doi.org/10.1016/j.tics.2021.03.015

Caviola, L., Schubert, S., \& Nemirow, J. (2020). The many obstacles to effective giving. Judgment and Decision Making, 15(2), 159.

Caviola, L., Schubert, S., Teperman, E., Moss, D., Greenberg, S., \& Faber, N. (2020). Donors vastly underestimate differences in charities' effectiveness. Judgment and Decision Making. https://ore.exeter.ac.uk/repository/handle/10871/122268

Connor, R. A., Glick, P., \& Fiske, S. T. (2017). Ambivalent sexism in the twenty-first century. In C. G. Sibley \& F. K. Barlow (Eds.), The Cambridge handbook of the psychology of prejudice (pp. 295-320). Cambridge University Press.

Coppock, A. (2018). Generalizing from Survey Experiments Conducted on Mechanical Turk: A Replication Approach. Political Science Research and Methods, 1-16.

Cosmides, L., Guzmán, R. A., \& Tooby, J. (2018). The evolution of moral cognition. Routledge.

Dullaghan, N. (2019, December 5). EA Survey 2019 Series: Community Demographics \& Characteristics - EA Forum. https://forum.effectivealtruism.org/posts/wtQ3XCL35uxjXpwjE/easurvey-2019-series-community-demographics-and

Eagly, A. H., Nater, C., Miller, D. I., Kaufmann, M., \& Sczesny, S. (2019). Gender stereotypes have changed: A cross-temporal meta-analysis of U.S. public opinion polls from 1946 to 2018. The American Psychologist. https://doi.org/10.1037/amp0000494

Earle, S., \& Read, R. (2016). Is it Effective? Should it be More Affective? The Philosophers' Magazine, 73, 84-91.

Eisenberg, N., \& Miller, P. A. (1987). The relation of empathy to prosocial and related behaviors. Psychological Bulletin, 101(1), 91-119.

Everett, J. A. C., Faber, N. S., Savulescu, J., \& Crockett, M. J. (2018). The costs of being consequentialist: Social inference from instrumental harm and impartial beneficence. Journal of Experimental Social Psychology, 79, 200-216.

Everett, J. A. C., Pizarro, D. A., \& Crockett, M. J. (2016). Inference of trustworthiness from intuitive moral judgments. Journal of Experimental Psychology. General, 145(6), 772-787. 
DOES MAXIMIZING GOOD MAKE PEOPLE LOOK BAD?

Faul, F., Erdfelder, E., Lang, A.-G., \& Buchner, A. (2007). G*Power 3: a flexible statistical power analysis program for the social, behavioral, and biomedical sciences. Behavior Research Methods, 39(2), 175-191.

Fetherstonhaugh, D., Slovic, P., Johnson, S., \& Friedrich, J. (1997). Insensitivity to the Value of Human Life: A Study of Psychophysical Numbing. Journal of Risk and Uncertainty, 14(3), 283300.

Fowler, Z., Law, K. F., \& Gaesser, B. (2021). Against Empathy Bias: The Moral Value of Equitable Empathy. Psychological Science, 32(5), 766-779.

Frank, R. H. (1988). Passions within reason: The strategic role of the emotions. W W Norton \& Co.

Frank, R. H., Gilovich, T., \& Regan, D. T. (1993). Does Studying Economics Inhibit Cooperation? Journal of Economic Perspectives, 7(2), 159-171.

Frequently Asked Questions and Common Objections. (n.d.). Effective Altruism. Retrieved October 28, 2021, from https://www.effectivealtruism.org/faqs-criticism-objections/

Giner-Sorolla, R. (2018, January 24). Powering Your Interaction. Approaching Significance. https://approachingblog.wordpress.com/2018/01/24/powering-your-interaction-2/

Giving USA 2020. (2020, June 16). Giving USA. https://givingusa.org/giving-usa-2020-charitablegiving-showed-solid-growth-climbing-to-449-64-billion-in-2019-one-of-the-highest-years-forgiving-on-record/

Goodwin, G. P., Piazza, J., \& Rozin, P. (2014). Moral character predominates in person perception and evaluation. Journal of Personality and Social Psychology, 106(1), 148-168.

Graziano, W. G., Habashi, M. M., \& Woodcock, A. (2011). Exploring and measuring differences in person-thing orientations. Personality and Individual Differences, 51(1), 28-33.

Hauser, D. J., \& Schwarz, N. (2015). It's a Trap! Instructional Manipulation Checks Prompt Systematic Thinking on “Tricky” Tasks. SAGE Open, 5(2), 2158244015584617.

Helion, C., \& Pizarro, D. A. (2015). Beyond Dual-Processes: The Interplay of Reason and Emotion in Moral Judgment. In J. Clausen \& N. Levy (Eds.), Handbook of Neuroethics (pp. 109-125). Springer Netherlands.

Helliwell, J. F., \& Putnam, R. D. (2004). The social context of well-being. Philosophical Transactions 
DOES MAXIMIZING GOOD MAKE PEOPLE LOOK BAD?

of the Royal Society of London. Series B, Biological Sciences, 359(1449), 1435-1446.

Henrich, J., Boyd, R., Bowles, S., Camerer, C., Fehr, E., Gintis, H., McElreath, R., Alvard, M., Barr, A., Ensminger, J., Henrich, N. S., Hill, K., Gil-White, F., Gurven, M., Marlowe, F. W., Patton, J. Q., \& Tracer, D. (2005). "Economic man” in cross-cultural perspective: Behavioral experiments in 15 small-scale societies. The Behavioral and Brain Sciences, 28(6), 795-815.

Henrich, J., Ensminger, J., McElreath, R., Barr, A., Barrett, C., Bolyanatz, A., Cardenas, J. C., Gurven, M., Gwako, E., Henrich, N., Lesorogol, C., Marlowe, F., Tracer, D., \& Ziker, J. (2010). Markets, Religion, Community Size, and the Evolution of Fairness and Punishment. Science, 327(5972), 1480-1484.

Henrich, J., Heine, S. J., \& Norenzayan, A. (2010). The weirdest people in the world? Behavioral and Brain Sciences, 33(2-3), 61-83.

Henrich, J., McElreath, R., Barr, A., Ensminger, J., Barrett, C., Bolyanatz, A., Cardenas, J. C., Gurven, M., Gwako, E., Henrich, N., Lesorogol, C., Marlowe, F., Tracer, D., \& Ziker, J. (2006). Costly Punishment Across Human Societies. Science, 312(5781), 1767-1770.

Hope Consulting, L. L. C. (2010). Money for good: The US market for impact investments and charitable gifts from individual donors and investors.

Hsee, C. K., Loewenstein, G. F., Blount, S., \& Bazerman, M. H. (1999). Preference reversals between joint and separate evaluations of options: A review and theoretical analysis. Psychological Bulletin, 125(5), 576-590.

Izuma, K., Matsumoto, K., Camerer, C. F., \& Adolphs, R. (2011). Insensitivity to social reputation in autism. Proceedings of the National Academy of Sciences, 108(42), 17302-17307.

Jaeger, B., \& van Vugt, M. (2022). Psychological barriers to effective altruism: An evolutionary perspective. Current Opinion in Psychology, 44, 130-134.

Jordan, J. J., Hoffman, M., Nowak, M. A., \& Rand, D. G. (2016). Uncalculating cooperation is used to signal trustworthiness. Proceedings of the National Academy of Sciences, 113(31), 86588663.

Kahane, G., Everett, J. A. C., Earp, B. D., Caviola, L., Faber, N. S., Crockett, M. J., \& Savulescu, J. (2018). Beyond sacrificial harm: A two-dimensional model of utilitarian psychology. 
DOES MAXIMIZING GOOD MAKE PEOPLE LOOK BAD?

Psychological Review, 125(2), 131-164.

Lakens, D. (2016, November 12). Why Within-Subject Designs Require Fewer Participants than Between-Subject Designs. http://daniellakens.blogspot.com/2016/11/why-within-subject-designsrequire-less.html

Lakens, D., Scheel, A. M., \& Isager, P. M. (2018). Equivalence Testing for Psychological Research: A Tutorial. Advances in Methods and Practices in Psychological Science, 1(2), 259-269.

Law, K. F., Campbell, D., \& Gaesser, B. (2019). Biased Benevolence: The Perceived Morality of Effective Altruism Across Social Distance. https://doi.org/10.31234/osf.io/qzx67

Lenth, R. (2018). emmeans: Estimated Marginal Means, aka Least-Squares Means. $R$ Package Version 1.3.0.

Levine, E. E., Barasch, A., Rand, D., Berman, J. Z., \& Small, D. A. (2018). Signaling emotion and reason in cooperation. Journal of Experimental Psychology. General, 147(5), 702-719.

Loewenstein, G., O’Donoghue, T., \& Bhatia, S. (2015). Modeling the interplay between affect and deliberation. Decisions, 2(2), 55-81.

Lykken, D. T. (1968). Statistical significance in psychological research. Psychological Bulletin, 70(3), $151-159$.

MacAskill, W. (2015). Doing Good Better: How Effective Altruism Can Help You Make a Difference. New York, USA: Gotham Books.

MacAskill, W. (2019). The definition of effective altruism. Effective Altruism: Philosophical Issues, 2016(7), 10.

McManus, R. M., Kleiman-Weiner, M., \& Young, L. (2020). What We Owe to Family: The Impact of Special Obligations on Moral Judgment. Psychological Science, 31(3), 227-242.

Metzger, L., \& Günther, I. (2019). Making an impact? The relevance of information on aid effectiveness for charitable giving. A laboratory experiment. Journal of Development Economics, $136,18-33$.

Montgomery, J. M., Nyhan, B., \& Torres, M. (2018). How Conditioning on Posttreatment Variables Can Ruin Your Experiment and What to Do about It. American Journal of Political Science, 62(3), 760-775. 
DOES MAXIMIZING GOOD MAKE PEOPLE LOOK BAD?

Oetting, P. (2018, November 30). 3 problems with effective altruism. https://blog.acton.org/archives/104963-3-problems-with-effective-altruism.html

Ord, T. (2013). The moral imperative toward cost-effectiveness in global health. Center for Global Development.

Pek, J., \& Flora, D. B. (2018). Reporting effect sizes in original psychological research: A discussion and tutorial. Psychological Methods, 23(2), 208-225.

Rege, M., \& Telle, K. (2004). The impact of social approval and framing on cooperation in public good situations. Journal of Public Economics, 88(7), 1625-1644.

Reyna, C. (2017). Scale Creation, Use, and Misuse: How Politics Undermines Measurement. In Politics of Social Psychology (pp. 91-108). Psychology Press.

Schubert, S., \& Caviola, L. (2021). Virtues for Real-World Utilitarians. https://doi.org/10.31234/osf.io/w52zm

Silver, N., \& McCann, A. (2014, July 20). How to Tell Someone's Age When All You Know Is Her Name. FiveThirtyEight; FiveThirtyEight. https://fivethirtyeight.com/features/how-to-tellsomeones-age-when-all-you-know-is-her-name/

Simler, K., \& Hanson, R. (2017). The Elephant in the Brain: Hidden Motives in Everyday Life. Oxford University Press.

Simmons, J. P., Nelson, L. D., \& Simonsohn, U. (2012). A 21 Word Solution. https://doi.org/10.2139/ssrn.2160588

Simons, D. J., Shoda, Y., \& Lindsay, D. S. (2017). Constraints on Generality (COG): A Proposed Addition to All Empirical Papers. Perspectives on Psychological Science, 12(6), 1123-1128.

Simonsohn, U. (2014, March 12). [17] No-way Interactions. Data Colada. http://datacolada.org/17

Simonsohn, U. (2015, April 23). [36] How to Study Discrimination (or Anything) With Names; If You Must. Data Colada. http://datacolada.org/36

Singer, P. (2013, March). The why and how of effective altruism. TED. https://www.ted.com/talks/peter_singer_the_why_and_how_of_effective_altruism

Small, D. A., \& Loewenstein, G. (2003). Helping a Victim or Helping the Victim: Altruism and Identifiability. Journal of Risk and Uncertainty, 26(1), 5-16. 
DOES MAXIMIZING GOOD MAKE PEOPLE LOOK BAD?

Small, D. A., Loewenstein, G., \& Slovic, P. (2007). Sympathy and callousness: The impact of deliberative thought on donations to identifiable and statistical victims. Organizational Behavior and Human Decision Processes, 102(2), 143-153.

Sperber, D., \& Baumard, N. (2012). Moral Reputation: An Evolutionary and Cognitive Perspective. Mind \& Language, 27(5), 495-518.

Trivers, R. L. (1971). The Evolution of Reciprocal Altruism. The Quarterly Review of Biology, 46(1), $35-57$.

Uhlmann, E. L., Pizarro, D. A., \& Diermeier, D. (2015). A Person-Centered Approach to Moral Judgment. Perspectives on Psychological Science, 10(1), 72-81.

Uhlmann, E. L., Zhu, L. (lei), \& Tannenbaum, D. (2013). When it takes a bad person to do the right thing. Cognition, 126(2), 326-334.

Wells, G. L., \& Windschitl, P. D. (1999). Stimulus Sampling and Social Psychological Experimentation. Personality \& Social Psychology Bulletin, 25(9), 1115-1125.

Yarkoni, T. (2020). The Generalizability Crisis. https://doi.org/10.31234/osf.io/jqw35

Yudkin, D. A., Prosser, A. M. B., \& Crockett, M. J. (2019). Actions speak louder than outcomes in judgments of prosocial behavior. Emotion , 19(7), 1138-1147. 